\title{
The mathematical anti-atomism of Plato's Timaeus
}

\author{
Luc Brisson \\ Centre Jean Pépin \\ CNRS-UMR 8230 \\ École normale supérieure \\ Paris Sciences Lettres
}

\author{
Salomon Ofman \\ CNRS-Institut mathématique de Jussieu- \\ Paris Rive Gauche \\ Sorbonne Université \\ Paris Université
}

\begin{abstract}
In Plato's eponymous dialogue, Timaeus, the main character presents the universe as an almost perfect sphere filled by tiny invisible particles having the form of four regular polyhedrons. At first glance, such a construction may seem close to an atomic theory. However, one does not find any text in Antiquity tying Timaeus' cosmology to the atomists, and Aristotle made a clear distinction between Plato and the latter. Despite the cosmology in the Timaeus is so far apart from the one of the atomists, Plato is commonly presented in contemporary literature as some sort of atomist, sometimes as supporting a so-called form of 'mathematical atomism'. The problem is that the term 'atomism', and even more so 'mathematical atomism', is rarely defined when applied to Plato. Since, it covers many different theories, there are almost as many different meanings as different authors. The purpose of this article is to consider whether it is right to connect Timaeus' cosmology to some kind of 'atomism', whatever the meaning attributed to 'atomism'. Thus, its purpose is double: to have a better understanding of the cosmology of the Timaeus, but also to consider the different modern 'atomistic' interpretations of this cosmology. Indeed, we would like to show that such a claim, in any form whatsoever, is misleading, and an impediment to the understanding of the dialogue, and more generally of Plato's philosophy.
\end{abstract}

We are happy to thank Pierre-Marie Morel and Carla Rita Palmerino for their readings and helpful remarks on the ancient atomists and on Cavalieri's theory of indivisibles respectively.

The main difficulty confronting the study of the alleged 'atomism' in the Timaeus is its polysemy, because of the multiplicity of theories referred to by the term 'atomism', and the lack of a precise definition of that term when used by modern authors. A first problem is the lack of texts by the atomists before or around Plato's times. What is known are brief fragments quoted by authors living many centuries later, or by Aristotle, who, however, quote them in a polemical and critical context. Hence, it is not easy to know the positions of the early atomists preceding Plato, essentially Leucippus and Democritus. ${ }^{1}$ The most important testimonies are those by Aristotle, although they always need to be considered with a 'grain of salt' because of his habit of taking for granted some of his own basic principles. Leucippus and Democritus are usually linked together, but even less is known about the former, and the texts discussing early atomism concern mainly Democritus.

\footnotetext{
${ }^{1}$ Since no works of Leucippus or Democritus have survived, our knowledge of early atomists depends 'on quotations in surviving authors, criticisms by their rivals, and summaries by the ancient historians of philosophy.' (Furley (1987), p. 115). Their life and doctrine 'must therefore be glued together from roughly 298 often strangely colored mosaic pieces that are scattered here and there in the doxographic literature.' (Luthy (2000), p. 448); cf. also Taylor-Christopher (1999), p. xi.
} 
A second difficulty is the existence, under the description of atomism, of different kinds of doctrines that are far apart from each other, covering a broad period of time, from circa the $5^{\text {th }}$ century BCE to today. Hence, it is not easy to decide which of them the modern commentators have in mind when they speak about 'atomism'. Moreover, the term has been extended to new fields, and Plato's cosmology has often been called a 'mathematical atomism' by modern scholars. However, again, this 'mathematical atomism' has different meanings, and this notion is far from being clear. This is why we think that a clarification is very much needed. The term 'atomism' is often used in such a vague way in modern scholarly literature, that it is difficult to know to which kind of atomism, ancient or modern, it refers. Thus, we need of course to consider the theories preceding Plato and the ones in Antiquity referring to them. ${ }^{2}$ However, the cosmology in the Timaeus has several times been connected to modern physical or mathematical theories. For instance, Andrew Gregory claims: 'It is also worth discussing how Plato's atomism is rather more like modern atomism than that of Leucippus and Democritus. Plato is strong on the idea that there are a small number of types of ultimate particles, which are mathematically well defined, against the indefinite number of shapes and sizes of the atomists.' ${ }^{3}$ Thus, to be fair and to avoid the charge that we consider the names rather than their meanings, we need, if only for didactical reasons, to consider these theories at least briefly. ${ }^{4}$

\section{Plato and 'physical atomism' 1. Plato and early atomists}

The first and most common meaning of 'atoms' concern the physical world, so that 'atomism' is considered, first and foremost, as a physical theory, especially when discussing the atomists in Antiquity. We begin with some general points of the claim that Timaeus' cosmology is founded on 'atomism', as it was understood around Plato's times. The main testimony is given in Aristotle's texts, especially in his treatise On the Heavens, and also in some parts of his treatise On the Generation and Corruption and also is a few passages in the Metaphysics. According to Aristotle's commentaries, there are fundamental differences between Plato and the ancient atomists:

\footnotetext{
${ }^{2}$ Namely, original texts of earlier atomists, essentially Leucippus and Democritus, are lacking. However, there are many modern studies on this subject based on fragments in later texts. For instance, O'Brien (1984), I; Furley (1987); Salem (2013) (in French); for texts and commentaries, cf. Taylor (1999) as well as the passages concerning the atomist philosophers in Diogenes Laertius, essentially Leucippus (IX, 30-33), Democritus (IX, 34-49) and Epicurus (book X). Here, we will consider mainly the questions related to Timaeus' cosmology.

${ }^{3}$ Gregory (2001), p. 15; and the $20^{\text {th }}$ century physicist, W. Heisenberg, argues that 'What is really needed is a change in fundamental concept. We will have to abandon the philosophy of Democritos and the concept of fundamental elementary particles. And, we should accept instead the concept of fundamental symmetries which is a concept out of the philosophy of Plato (...) we are probably forced, in our concepts, to abandon the atomic materialism of Democritus and turn to the ideas of symmetry in the philosophy of Plato' (Heisenberg (1973), p. 10).

${ }^{4}$ An example of such an anachronistic though popular claim is the following text from the Standford Encyclopedia of Philosophy: 'Infinitesimals have a long and colourful history. They make an early appearance in the mathematics of the Greek atomist philosopher Democritus (c. 450 B.C.E.), only to be banished by the mathematician Eudoxus (c. 350 B.C.E.) in what was to become official "Euclidean" mathematics.' (Bell (2017), §0; included again in Bell (2019), p. xi). For some examples of links established between the Timaeus and modern physics, cf. for instance Taylor (1928), in particular, p. 90-93, as well as Gregory (2001), Heisenberg (1973), Leggett (2010), ...
} 
a) For the atomists, there are many, even an infinite number of different universes; ${ }^{5}$ for Plato, only one.

b) For the atomists, our universe is spatially infinite; for Plato, it is a finite sphere.

c) For Plato, this sphere is completely filled without any void; ${ }^{8}$ even the gaps between particles are continually filled. 'In the atomists' many universes, the 'atoms' must move in a spatial void. ${ }^{10}$

d) Timaeus' universe is made up of particles shaped as four regular polyhedrons: the tetrahedron, the octahedron, the icosahedron and the cube, corresponding respectively to the four elements: fire, air, water and earth. ${ }^{11}$ For the atomists in Antiquity, these particles have many, perhaps an infinite number of different arbitrary shapes ${ }^{12}$ and sizes.

e) In the Timaeus, the polyhedrons are limited by equilateral triangles or squares, which are themselves composed from two basic right triangles (53c-54a). Polyhedrons are not indivisible; they are continually obliterated into these triangles, which, in turn, are continually brought together to produce polyhedrons $(56 \mathrm{~d}-57 \mathrm{c})$. These polyhedrons are the opposite of atoms i.e. ultimate particles.

f) For the atomists, the behavior of the atoms when they encounter depends only on their mechanical properties, that is their sizes and speeds. ${ }^{14}$ For Plato, the result is entirely different, depending on whether the elementary particles encounter ones of the same element or of another element. In the former case, they will bind together (57a); in the latter case, the particles of one of these elements will break down into right triangles, scalene for particles of fire, air and water, isosceles for earth (57b-c). Again, the result depends on the kind of element involved. In general, scalene triangles will give rise to

\footnotetext{
5 ،... although both Plato and Leukippos postulate elementary constituents that are indivisible and distinctively characterized by figures, there is this great difference between the two theories [those of Leukippos and Plato]: the indivisibles of Leukippos are solids, while those of Plato are planes' (On Generation and Corruption, 325b25, H. Joachim transl.; our emphases). Cf. also, On the Heavens, III, 7, 30, 306a27-b3.

${ }^{6} 31 \mathrm{a} 2-\mathrm{b} 4,30 \mathrm{c} 5,30 \mathrm{~d} 3-31 \mathrm{a} 1$.

${ }^{7}$ 33a7. This is a misnomer since the universe is a spatial body while the sphere is the surface limiting this body. A more exact word would be instead a 'ball', as it is called in modern mathematics. Nevertheless, it is the usual name given in scholarly studies on Plato, so that we will stand by this term.

${ }^{8}$ Timaeus 58a-b; 59a; 60c; 79a-b; 79b-c; 80c; 81b. Regarding the way the particles are able to move in a universe without void, see 58b2-c4; 60e4-61b6.

${ }^{9}$ The existence of such gaps in a space filled by the four regular polyhedrons is one of the criticisms of Aristotle against the cosmology of the Timaeus, a proof of inconsistency (On the Heavens, 306b3-9). Some scholars consider the answer is easy, Plato does not bother with small voids refuting only large-scale ones (O’Brien (1984), p. 359 ff.). However, Aristotle considers that to accept small voids but not large ones is absurd (On Generation and Corruption, 326b17-21) and the impossibility of the void is too important to be reduced to a question of sizes, as shown by the number of times Timaeus denies its existence (cf. previous note), and as it is connected to the essential question of the non-being. This problem will be dealt with in a subsequent article.

${ }^{10}$ Metaphysics I, 4, 985b4-10; again III, 5, 1009a25-30.

${ }^{11}$ 55c4-6. This division into four elements was a common assumption going back at least to Empedocles (DK 31 A37 = Metaphysics A, 4, 985a31-33). It was assumed by most ancient Greek, perhaps including Democritus, as is usually understood from a passage of Aristotle's Treatise On the Heavens (III, 7, 305a34-b28). However, it is not clear whether this concerns Democritus' theory or its reinterpretation by Aristotle in his own terms (cf. Cherniss (1935), p. 10, note 42).

${ }^{12}$ Aristotle's On Generation and Corruption I, 1, 314a22-23, also III, 1, 325b27-28; I, 1, 315b9; On the Heavens, III, 4, 303a10.

${ }^{13}$ O'Brien considers that although the shapes of the atoms are infinite in number for Democritus, the claim about the infinite number of their sizes is a consequence of prejudice and/or (perhaps unconscious) presuppositions (O’Brien (1982), p. 193-197). For a different view, see Brunschwig (1997), p. 497-498.

${ }^{14}$ In modern terms, the momentums and kinetic energies of the particles.
} 
particles of fire, air or water; isosceles triangles will remain the same until they meet other particles of earth.

It would be easy to multiply the differences between the cosmology of the Timaeus and atomism on almost every point. Aristotle usually opposes them to each other, though in a few instances, ${ }^{15}$ he does not hesitate to put Plato alongside Democritus and Leucippus. Thus, some scholars claim, following Aristotle's authority, that there are some similarities between both cosmologies. ${ }^{16}$ However, it appears that Aristotle's purpose, in these texts, is to reject both because they disagree with his principle of unlimited division of spatial bodies, not to find some common grounds between Plato and the atomists. On the one hand, Aristotle emphasizes the difference between both doctrines. ${ }^{17}$ On the other hand, although an outspoken adversary of the atomists, he goes as far as to defend them against Plato on this point, because he considers the latter to be even further from his theses than the former. ${ }^{18}$ Hence, there is no testimony that allows Plato to be reconciled with the ancient atomists. ${ }^{19}$ Thus to complete the comparison between the cosmology in the Timaeus and 'atomism', is it possible to find some link between Plato and 'atomism' in its modern sense?

\section{Plato and modern atomism}

With the exception of the existence of the void, most of the ancient atomists' theses (cf. points a)-f) in the previous paragraph), are also rejected by modern atomists, who nevertheless claim a certain filiation with the ancient theses. ${ }^{20}$ Is it therefore possible to consider that Timaeus' cosmology is based on some form of atomism in the modern (and vague) sense? If some unity is to be found between all the 'atomists', past and modern, besides the existence of the void, it would be that the whole universe is constructed out of (tiny) unbreakable ${ }^{21}$ eternal particles.

As seen above, atomism requires the existence of void, ${ }^{22}$ while by contrast, there is no void in Timaeus' universe. However, is it even possible to consider that Timaeus' elementary polyhedrons are similar in any way to modern atoms? ${ }^{23}$ Namely, contrary to the latter, Timaeus' polyhedrons are continually generated out of and destroyed into the triangles that form the faces of these polyhedrons. ${ }^{24}$ On this basis, some commentators have argued that these triangles are

\footnotetext{
${ }^{15}$ For instance, On the Heavens, III, 8, 306b30-307a30.

${ }^{16}$ Cf. Gregory (2003), p. 38-39. Vlastos begins his article on The Disorderly Motion in the Timaios, by: 'In what sense is the Timaios a myth? A comparison with the atomists suggests itself at once. The Timaios corrects their views in their own universe of discourse' (Vlastos (1939), p. 71).

${ }^{17}$ On Generation and corruption, 325b27-29.

${ }^{18}$ On the Heavens, V, 2, 308b30-32.

${ }^{19}$ Taylor goes as far to write that Plato knew 'little or nothing of the atomists' (Taylor (1928), p. 39).

${ }^{20}$ Besides Leucippus and Democritus, mainly Epicurus and Lucretius.

${ }^{21}$ As noted previously, it is difficult to answer many questions about the atomists, as for instance how large the atoms can be (cf. supra, notes 13 and 13), since no text of the first atomists has survived. Nevertheless, it is reasonably certain that these particles were unbreakable, which is the very definition of the Greek term ' $a$-tomon', although even this is debated by some scholars (cf. Makin (1989) and infra, note 83).

${ }^{22}$ See Melissos DK 30B7 = LM21D10, and also supra, note 9.

${ }^{23}$ Here 'modern atomism' refers to the prevalent theory in the $19^{\text {th }}$ century originating in Dalton's chemical construction (cf. for instance Greenaway (1966), p. 132-133 on Dalton's book New System of Chemical Philosophy published between 1808-1810). To quote L. Whitt, 'Many (but not all) physicists and chemists of the XIXth century claimed to give the answer: "Yes, chemical atoms are indivisible and eternal.", (Whitt (1961), p. 21). In contemporary physics, an 'atom' is anything but an 'a-tom' (i.e. indivisible), as already noted by Taylor ((1926), p. 298). However, these atoms have lost their etymological meaning, and indeed, these almost indefinitely divisible contemporary 'atoms' do not help to clarify the sense of 'atom' when used by scholars, especially when they do not provide any clear definition of what they mean when they use it.

${ }^{24}$ Cf. supra, point 1.e).
} 
not geometrical objects, but very thin physical particles, similar to tiles, and possessing three dimensions, length, width and depth. ${ }^{25}$ Unfortunately, as Cornford already emphasized, this is not consistent either with Plato's text, or with ancient testimonies. ${ }^{26}$ In particular, it contradicts an issue on which Plato sets himself apart from his predecessors: contrary to the latter, for Plato, the universe is built not only on physical but mainly on mathematical principles.

Accordingly, to circumvent these difficulties, and to maintain, according to a certain reading of Aristotle's texts some link between Timaeus' cosmology and 'atomism', many modern scholars have proposed to replace the common (physical) atomism by some so-called 'mathematical atomism'. Ths new 'atomism' is supposed to be different from the 'classical' one, and the inconsistencies between 'classical' atomism and the Timaeus, as seen above, to disappear when one considers this new form of 'atomism'. So, let us consider whether this is warranted.

\title{
II. An intermediate form of 'mathematical atomism': the elementary polyhedrons
}

A first form of a 'mathematization' of atomism is to consider that the atoms are the four regular polyhedrons corresponding to the four elements. As the smallest geometrical possible particles, thus as particles they are indivisible, they may be said atoms. It is an intermediate between physics and mathematics, because on the one hand these polyhedrons are physical particles composing the four elements, thus the whole universe. But, on the other hand, they are geometrical figures, whose faces are mathematical plane surfaces (squares or equilateral triangles). ${ }^{27}$ This is for instance the position of William Pohle presenting these particles as atomic in a paper critical of Cornford's analysis. ${ }^{28}$

\begin{abstract}
Despite his hostility to several aspects of Democritean atomism, Plato presents the reader of the Timaeus with a sophisticated account of physical change at the macroscopic level in terms of an atomic particle physics rich in mathematical structure. In particular, he offers an elaborate theory concerning the structure and behavior of microscopic particles of earth, air, fire, and water - the four elements according to Greek tradition - to which he assigns the shape of four of the five regular polyhedra. According to this theory, all sensible bodies are composed of four different types of corpuscles-earth, water, air, and fire-understood as generic terms rather than proper names, each of which is conceived to have a distinctive configuration. Thus the physical world on the Platonic model is ultimately composed of "earth-cubes," "watericosahedra," "air-octahedra," and "fire-tetrahedra.".
\end{abstract}

\footnotetext{
${ }^{25}$ Cf. Martin (1841), II, p. 241-2. Already in Antiquity, Proclus, quoted by Simplicius, supported this thesis in defense of Plato against Aristotle's attacks (Simplicius-2, 577. 17-19), as did Simplicius himself (ibid., 563.26564. 3, 573. 3-11, 577. 17-19). Andrea Falcon writes: 'Proclus conceived of the elementary triangles as solids, and read the Timaeus as claiming that these triangles possess also depth; that is, they possess a minimal thickness' adding even in a note that 'The hypothesis of a minimal thickness of the elementary triangles was influential in antiquity.' (Falcon (2005), p. 47; author's emphasis). Moreover, according to Falcon, such interpretation may be even found much earlier, already in Epicurus' writings (Epicuro, Della Natura, libro XIV, col. XXXVIII, Leone (1984)). However, this would entail that Timaeus' cosmology is based on some form of atomism, an interpretation rejected by Aristotle.

${ }^{26}$ Cornford (1937), p. 229.

However, even for atomists, the 'atoms' may have some mathematical forms. According to Aristotle, Democritus' atoms of fire were spheres (cf. in particularly, On the Heavens III, 4, 303a12-16).

${ }^{28}$ Cornford wants to understand how particles of different sizes can be generated by only two right triangles, and to explain the endless diversity of natural bodies. The main difficulty is that these particles have to respect the 'laws of transformation' (cf. supra, note 26)

${ }^{29}$ Pohle (1971), p. 36. The term atomism is used in a vague sense since no precision is given which kind of atomism is considered, a common cause of confusion. To still call 'atoms' what is not 'indivisible' may be better understood when we consider the modern sense of atoms, which are called such, despite they are certainly not indivisible. A common problem when modern speak about 'atoms', they more often than not, mix ancient meaning and modern ones.
} 
However, a few lines later, Pohle adds a non-insignificant caveat: these supposed atoms are not 'a-toms' i.e. 'in-divisible', since they may be divided by their mutual interaction. ${ }^{30}$

The same position is adopted by Andrew Gregory, explaining how we need to understand the term 'Geometrical atomism' abridged in 'GA':

By geometrical atomism I mean the theory that the elements (earth, water, air, fire) can be analysed into three-dimensional particles of definite shape (cubes, octahedra, eikosahedra, tetrahedra, which I shall call 'atoms', in the modern sense),

and as Pohle, he adds nevertheless:

these particles can be further subdivided into planes, and that these planes can be further subdivided into one of two types of triangles. (Gregory (2003), p. 29).

One encounters, once again, the problems surrounding the meaning of 'atom' among the advocates of a 'mathematical atomism' in Plato. Are the 'atoms' the corporeal elementary polyhedrons, i.e. the smallest elementary particles, or the geometric triangles that compose their faces? The commentators often hesitate between these two cases. ${ }^{31}$ Even when they acknowledge that Timaeus' basic objects are mathematical triangles, not particles, they nevertheless often argue that Timaeus' construction is a 'mathematical atomism' because these particles are the smallest (spatial) bodies, and their shapes are regular polyhedrons, hence geometrical figures. ${ }^{32}$ Thus, the fundamental feature of Timaeus' elements, the composition/decomposition of the particles into/from triangles disappears, and the polyhedrons appear as the first principle of physics. Such a similar view is found largely in the literature at large. Let us just give an example. Under the subtitle 'Atoms as lumpish corpuscles' in the article on 'Atomism' in the Encyclopedia Britannica written by Andrew van Melsen, we find:

\begin{abstract}
'Another interesting form of atomism with inherently qualitied atoms, also based on the doctrine of the four elements, was proposed by Plato. On mathematical grounds, he determined the exact forms that the smallest parts of the elements must have. Fire has the form of a tetrahedron, air of an octahedron, water of an icosahedron, and earth of a cube. Inasmuch as he characterized the atoms of the four elements by different mathematical forms, Plato's conception can be considered as a transition between the qualitative and quantitative types of atomism.' (our emphasis). ${ }^{33}$
\end{abstract}

\footnotetext{
${ }^{30}$ 'Strictly speaking, these corpuscles are not themselves the atoms of Plato's system, since each is capable of being cut up by other corpuscles during various sorts of "chemical" or transformational reactions.' (Pohle (1971), p. 36). Let us remark that, while this is true for chemical particles, strictly speaking it is not true for the alleged 'atomic' (i.e. smallest) elementary particles in the Timaeus. These particles can only be broken by particles of another element (cf. supra, point I.1.f)). Sarah Broadie argues that they are atoms, 'three-dimensionally speaking' (Broadie (2011), p. 192, n. 46), but such a restriction would obliterate the very principles of Timaeus' cosmology as well as Aristotle's testimonies about it. This strange paradox of atoms which are not a-toms is not so uncommon, since in contemporary science (i.e. in $20^{\text {th }}$ century physics), almost indefinitely divisible particles are still called atoms (cf. supra, §I.2). However, while it is indeed an etymological misnomer, for Greek scientists it would be a pure absurdity, as the very definition of an 'atom' is unbreakability. These surprising inconsistent claims about divisible 'atoms' are probably connected to Aristotle's criticism that putting planes together can only yield mathematical bodies, not physical ones (On Generation and Corruption I, 2, 316a3-4). Thus, Aristotle's reading may entail that Timaeus' polyhedral are geometrical objects, while for Timaeus, they are particles of the four elements.

${ }^{31} \mathrm{Cf}$. for instance, infra, note 3. There are good reasons for such hesitation, cf. infra, §IV.2.

${ }^{32}$ For instance, Gregory (2008), p. xviii-xix, where letters and syllables are the models for triangles and elements. A little later, he makes a (favorable) comparison between Plato and Democritus/Leucippus, based on the difference between their elementary particles, not the triangles (p. lii); while Artman-Schäffer claim that Plato is correcting Democritus' atomism using polyhedrons (cf. (1993), p. 257). However, the interpretation of the four elements as letters or syllables is rejected by Timaeus (48b3-c2).

${ }^{33}$ Contrary to Pohle's article, the proviso that the polyhedrons are composed from and destroyed into triangles, is entirely forgotten in this text.
} 
Hence, Timaeus' universe is conceived as made of 'atoms' in the common sense of the term 'atom'. Such a conception is contrary to Timaeus' construction based on mathematical triangles. In particular, it negates the fundamental 'laws of transformation' between elements, that is the possibility of some elements to change into another one. For instance a particle of air, that is an octahedron, may give two particles of fire, that is two tetrahedrons (56e1-2). The similarity with formulas in modern 'atomic' chemistry, ${ }^{34}$ had lead many commentators to compare the two. However, Timaeus uses also fractions of polyhedrons in his formulas, as for instance when some particles of air are disintegrated, then 'two whole forms of air and a half would compose a single, entire form of water (Timaeus 56d-e). ${ }^{33}$ Namely, such a formula shows, once again, that Timaeus does not consider the regular polyhedrons as atoms. Moreover, these laws are based on the surfaces, not on the volumes of the particles. For instance, a particle of air, that is an octahedron, may produce two particles of fire, that is two tetrahedrons (56e1-2). This would be impossible when one considers these particles as atoms. First because atoms are supposed to be unchanging, ${ }^{36}$ while Timaeus' elementary particles are continually coming to be and passing away via the assembling or breaking down of the triangles forming their faces. ${ }^{37}$ But first and foremost because the transformations are based on the counting of their faces, not their volumes. An octahedron is formed by 8 equilateral triangles, twice the number of equilateral triangles forming a tetrahedron. This is obviously wrong if the ratio of the volume of an octahedron to a tetrahedron was considered. Namely, as shown in the Figure 7 of the Annex at the end of the article, a simple cutting proves that the volume of the former is four times the volume of the latter. ${ }^{38}$

\section{A geometrical 'mathematical atomism'}

Contrary to 'physical' atomism which has a long history in physics and among physicists (or natural philosophers), there is nothing similar for 'mathematical atomism' with respect to mathematics. In other words, this is an innovation of modern Platonist scholars. We know very little about the existence, if any, of some theories of 'mathematical atomism' in Antiquity. Neither do we know if any theory was called or called itself a 'mathematical atomism'. Hence, any discussion on Plato's alleged 'mathematical atomism' entails a review of some hypothetical theories referring to some hypothetical authors. Since a common feature of the so-called 'mathematical atomism' is its opposition to Aristotelian continuum, a general definition seems to be any theory based of some kind of mathematical atoms. In other words, a theory claiming the 'existence of mathematically indivisible spatial units' i.e. indivisible geometrical parts or

\footnotetext{
${ }^{34}$ For instance, the law which explains that two atoms of hydrogens can form one of helium.

${ }^{35}$ This seems so contrary to common sense that some scholars, Vlastos for example, thought that a correction was needed, and changed these formulas into whole numbers (Vlastos (1995), p. 71).

${ }^{36}$ Cf. supra, point I.1.e) and also note 23. Although he is sometimes quoted as a scientific authority for a supposed Platonic atomism, W. Heisenberg notes that: 'If the regular solids, which represent the four elements, can be compared with the atoms at all, it is made clear by Plato that they are not indivisible. Plato constructs the regular solids from two basic triangles, the equilateral and the isosceles triangles' (Heisenberg (1962), p. 68).

${ }^{37}$ This is done in two steps. First some basic right triangles, respectively four isosceles or six half equilateral, are joined together to form a square or an equilateral triangle respectively; then, these squares or equilateral triangles join to form the surfaces limiting the four regular polyhedrons corresponding to the four elements. The converse process occurs, when these polyhedrons are dissolved in turn into the basic right triangles.

${ }^{38}$ That the volume of the different regular polyhedrons was known in Plato's, a fortiori, Socrates' times had been the object of numerous discussions between historians of mathematics as well as commentators of Plato. However, at least one case, the change between air and fire, is obviously inconsistent with the law of transformations, and certainly known in Plato's (and even Socrates') times. We give two elementary proofs in the Appendix at the end of the article.
} 
atoms such that any figure is an addition of a finite number ${ }^{39}$ of such parts. As Harold Joachim presents it, such a theory:

maintains that in dividing any quantum, of whatever kind, you will ultimately come to indivisible constituent quanta of the same kind. Every line, e.g., is composed of a finite number of indivisible lines: every solid of a finite number of indivisible solid constituents, i.e. solids not further divisible into solids.' (Joachim (1908), 968a2, note 1).

\title{
1. The puzzles of 'mathematical atoms'
}

The existence of indivisible, thus smallest, geometrical magnitudes or 'atoms' is inconsistent with almost all of geometry, and especially with the existence of irrational magnitudes. It seems clear that there were doctrines in Antiquity that did not take into account mathematics as an important science. As a matter of fact, Proclus speaks of people who either refused the first principles of mathematics (in particular 'axioms') or only the deductions from these principles:

\begin{abstract}
Now we have summed up these matters, it remains for us to examine the propositions that come after the principles. Up to this point we have been dealing with the principles, and it is against them that most critics of geometry have raised objections, endeavoring to show that these parts are not firmly established. Of those in this group whose arguments have become notorious some, such as the Sceptics, would do away with all knowledge, like enemy troops destroying the crops of a foreign country, in this case a country that has produced philosophy, whereas others, like the Epicureans, propose only to discredit the principles of geometry. Another group of critics, however, admit the principles but deny that the propositions coming after the principles can be demonstrated unless they grant something that is not contained in the principles. (Proclus, p. 156)
\end{abstract}

The important point is that the Epicureans, including probably Epicurus himself, rejected mathematics, and first and foremost their methods. A little later, Proclus writes that:

Since some persons have raised objections to the construction of the equilateral triangle with the thought that they were refuting the whole of geometry, we shall also briefly answer them. The Zeno whom we mentioned above asserts that, even if we accept the principles of the geometers, the later consequences do not stand unless we allow that two straight lines cannot have a common segment. For if this is not granted, the construction of the equilateral triangle is not demonstrated. Let $\mathrm{AB}$ be the straight line, he says, on which we are to construct the equilateral triangle. Let the circles be drawn, and from their point of intersection draw the lines CEA and CEB having CE as a common segment. It then follows that, although the lines from the point of intersection are equal to the given line $\mathrm{AB}$, the sides of the triangle are not equal, two of them being shorter than $\mathrm{AB}$. But if their equality is not established, neither are its consequences. Therefore, says Zeno, even if the principles be granted, the consequences do not follow unless we also presuppose that neither circumferences nor straight lines can have a common segment. (ibid., p. 170).

The figure accompanying the text is the one below:

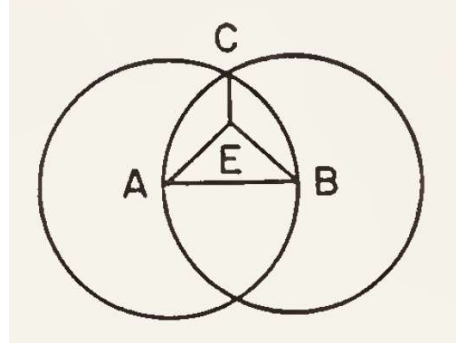

Figure 1

Hence, if we accept the existence of minimal straight lines (in the above figure CE for instance), even the construction of an equilateral triangle fails. Since this is the first proposition of the

\footnotetext{
${ }^{39}$ Some historians will even consider a more general case and the number of such parts may be infinite, as the Cavalieri's construction that is sometimes assigned, under a more primitive form, to Archimedes and Democritus (cf. infra, §2.iii)).
} 
first book of Euclid's Elements, the purpose of such claim is to at least the geometrical books of Euclid's Elements.

To summarize, let us quote David Sedley of the consequences of such a 'mathematical atomism' for geometry:

Epicurus believed in a minimal unit of measure out of which not only atoms but also all larger lengths, areas, and volumes are composed, is nowadays widely accepted; and most would also agree that it is not merely a physical minimum, contingent upon the nature of matter, but a theoretical minimum, than which nothing smaller is conceivable. Others both before and since Epicurus have been seduced by similar theories without being led to reject conventional geometry. Yet this is precisely the penalty which a theory of minimal parts should carry with it. (Sedley (1976), p. 23; our emphasis).

That this concerns later thinkers than Plato or Socrates, or even if Epicurus himself or only some of his followers had this position does not really matter, for it shows that the existence of 'atoms' of lines is incompatible with the proposition of the geometry in Antiquity. Likewise, the anthyphairesis algorithm, probably used for approximations by early Greek mathematicians, requires the idea of unlimited divisions, thus of unlimited small magnitudes, ${ }^{40}$ as well as Plato's method of definition based on arbitrary long series of successive dichotomies. ${ }^{41}$ As a matter of fact, such a doctrine is inconsistent with almost all of geometry, and especially with the existence of irrational magnitudes. ${ }^{42}$ Namely, this is still maintained by atomists several centuries later, as shown by Lucretius ( $1^{\text {st }}$ century CE) in his famous poem which makes fun of a supposedly spherical earth. ${ }^{43}$ With a world able 'to stand firm without the help of external blows', with 'heavy objects in the antipodes pressing upward and resting 'on the earth in a reversed position'; animals roaming 'upside down' and not dropping off 'the earth into the regions of the sky below'; 'inhabitants of the antipodes see[ing] the sun when we are looking at the stars of the night; 'shar[ing] the seasons with us alternately'; 'their nights correspond[ing] to our days' and so on.

Hence, there were indeed people and schools in Antiquity that support 'mathematical atomism', first and foremost the atomists. We will now inquire whether this was mainly starting Epicurus or earlier, before Plato's and Socrates' times. The best candidate for such a theory is of course Democritus. So let us consider whether this is reasonable, what would be its content and whether Plato's Timaeus can be connected with such theory.

\section{Democritus' 'physical' or 'mathematical' atomism?}

The lack of Democritus' texts constrains modern scholars to try to reconstruct his thinking through indirect quotations and many speculations on their part. One point is particularly debated: ${ }^{44}$ how deep-reaching was his atomism? Did it only concern the physical world or did it also include mathematics? In other terms, was he an 'atomist' in mathematics, that is does he consider that everything in mathematics is composed of a finite number of indivisible magnitudes? ${ }^{45}$ In other words, was he a 'mathematical atomist'? Since as we saw such theory is inconsistent with a large part of mathematics, an essential step to answer these questions is whether, as often claimed, Democritus, was a mathematician himself. One strong argument in

\footnotetext{
${ }^{40}$ Cf. Proclus, p. 217.

${ }^{41}$ See for instance, Proclus' Commentary on the first book of Euclid's Elements (277.25-279.4), quoted with some explanations in Heath (1908), p. 268. Cf. also, infra, note 101.

${ }^{42}$ Cf. Sedley (1976), p. 128

${ }^{43}$ De Natura Rerum I, 1050-1070.

${ }^{44}$ 'There is no agreement among these authorities as to whether or not Democritus believed in the existence of mathematically indivisible spatial units' (Hahm (1972), p. 206, n. 3; our emphasis); also Bell (2019) p. 9.

${ }^{45}$ 'The question whether the atoms were not only physically but also theoretically or mathematically indivisible has naturally aroused great interest among historians of mathematics.' (Guthrie (1965), p. 396).
} 
this direction is that he gave the volume of the pyramid. Namely, Archimedes in his treatise, the Method, ${ }^{46}$ ascribed to Democritus its formula, but not its mathematical demonstration ascribed to another one. ${ }^{47}$ Along the same lines, a text by Plutarch ascribes to Democritus a problem concerning the cone: whether all the plane sections parallel to the basis of a cone are equal or unequal (On Common Notions, 1079e-f). Moreover, several mathematical books (see Diogenes Laertius IX 46-49) are ascribed to Democritus, including a treatise On Irrational Lines and Solids. This is supposed to show that he was a high-level mathematician. Except of Archimedes' sentence, the two other arguments are extremely weak. There is no agreement on how to understand Plutarch's text or its purposes, and no one knows anything about the contents of Democritus' books, which they are all lost. There are even good reasons to doubt of the mathematical content of these works. ${ }^{48}$

\section{i) Democritus and the volume of the pyramid}

A question arises immediately: How did he obtain the formula? Some modern scholars claim he did it through a primitive method similar to Cavalieri's one ${ }^{49}$ that uses an in(de)finite number of lines or surfaces. ${ }^{50}$ However, this is extremely dubious since already by the ancient Greeks, this leads to many inconsistencies, as presented in the well-known paradoxes of Zeno. According to Archimedes, it was not a proof admissible by mathematicians. However, it was neither worthless from a mathematician point of view, as Archimedes uses it as an example of the importance to obtain a mathematical result, even if it is not completely proved according to mathematical standards. Moreover, at Democritus' times, the distinction between mathematical and physical spaces was not clear, as shown by Aristotle's sharp criticism of his predecessors. Namely, based on such 'mathematical atomism', the unbreakability of atoms whatever the force applied to them, would be put on solid theoretical ground rather than on some arbitrary physical hypotheses. It would be also in agreement with the attribution to Democritus of the computation of the volume of the pyramid, ${ }^{51}$ since the figure may be reduced to a finite addition of very thin 3-dimensonal plates. Thus, it is more reasonable to consider that Democritus obtained the formula through a finite construction, like the one in the figure below, without venturing into the trouble of infinite lines or surfaces:

\footnotetext{
${ }^{46}$ Heath (1913), p. 13; Heiberg (1913), p. 43.

${ }^{47}$ Probably Eudoxus, cf. On the Sphere and Cylinder, preface of book 1 (cf. Netz (2013), p. 32).

${ }^{48}$ Cf. for example Berryman (2016), §6.

${ }^{49}$ For instance, Bell (2019), p. 44; Heath (1921), p. 179-180; Christoph Scriba's and Peter Schreiber's 5000 Years of Geometry: Mathematics in History and Culture by, Birkhauser, 2015, p. 349; David Perkins' Calculus and Its Origins, The Mathematical Association of America, 2012, p. 43; a position apparently supported by Otto Toeplitz though not without some hesitation in his book The Calculus: A Genetic Approach, University of Chicago Press, 2007 (1963), p. 61.

${ }^{50}$ The same is said of Archimedes' construction in his Method. We will briefly present Cavalieri's theory, its interest but also its flaws in §iii), infra.

${ }^{51}$ As in modern mathematics, the base of a pyramid is not necessarily a square. For instance, in Timaeus (56b4-5), ' $\pi v \rho \alpha \mu$ í $\varsigma$ ' refers to the tetrahedron, that is a 'pyramid' of base a triangle. The volume either of a pyramid or a cone is one third of the product of its base by its height. For simplicity, we will consider the easiest case, the volume of the 'true' pyramid, that is with a square as base, though the same method is valid for a pyramid of any base, as well as for the cone.
} 


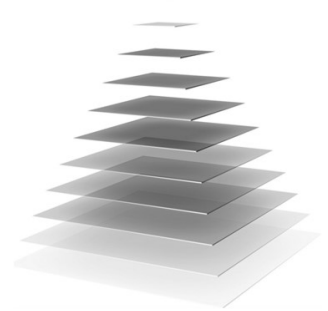

Figure 2

Its volume is then considered as the sum of many very thin parallelepipeds. For a mathematician, this is no more acceptable than the identification of a circle with a polygon, which Aristotle blamed on Antiphon. ${ }^{52}$ However, if one agrees with this identification, it is not too difficult to obtain the volume of the pyramid. Let us consider two possible ways to obtain it. The first consists in computing directly; however, this would require the knowledge of:

1) the general formula for the sum of the squares of the $n$ first integers, ${ }^{53}$

2) that when this number $n$ is very large, this sum is close to one third of the cube of $n .{ }^{54}$

It is hard to confirm or disprove these hypotheses with any degree of confidence, although this seems dubious.

A more reasonable possibility would be first to deduce from the above figure that the volume of the pyramid is proportional to the product of its base by its height, ${ }^{55}$ and then, to infer that any cube is the sum of six identical pyramids, with bases the six respective faces of the cube, as shown in the figure below, to finally conclude that the volume of each pyramid is equal to one third of the product of its base by its height. ${ }^{56}$



Figure 3

\section{ii) Democritus and mathematics}

a) Vlastos' argumentation

This result was considered so beautiful that it was still in the memory of mathematicians several centuries after its discovery. It seems to entail that Democritus was, among other things, a mathematician. ${ }^{57}$ However, this is inconsistent with Aristotle's testimonies that Democritus'

\footnotetext{
${ }^{52}$ Physics I, 2, 185a14-17.

${ }^{53}$ In modern symbolism, that Democritus knew the formula:

$$
1+2^{2}+3^{2}+\ldots+n^{2}=\frac{n(n+1)(2 n+1)}{6}
$$

${ }^{54}$ I.e., from the formula in the previous note, that for large $n$, a good approximation of $1+2^{2}+3^{2}+\ldots+n^{2}$ is $n^{3} / 3$.

${ }^{55}$ Because the volume of a parallelepiped is the product of the base by its height.

${ }^{56}$ Because the volume of a pyramid depends only of his base and height. Such a construction would moreover match well with Plutarch's account of Democritus and the cone (cf. supra, note 50). For an analysis of this text and the different possible interpretations, cf. Morel (2001). Let us also remark that a computation of the volume of a pyramid is found in much earlier mathematics (cf. the problem M14 and its numerical result in Moscow papyrus. For its interpretation, see for instance, Imhausen (2016), p. 73-76).

${ }^{57} \mathrm{He}$ is commonly presented as a universal thinker. For instance, Heath claims that 'there was no subject to which he did not notably contribute, from mathematics and physics on the one hand to ethics and poetics on the other
} 
theory was opposed to the very fundamental principles of mathematics, according to the words of Aristotle. ${ }^{58}$ According to the latter, Democritus' atomism was not limited to the physical world, the natural bodies, but also to mathematics. In other words, his atomism was a 'mathematical atomism'. As seen previously ( $\$ 1$, supra), the latter is opposed to a large part of the mathematics, so that it is completely inconsistent with a Democritus mathematician. Admittedly, it may be argued that, as a fierce critic of atomism, Aristotle would have wanted to present his adversaries in an unfavorable light. ${ }^{59}$ Since scholars disagree of this fundamental point, let us consider the arguments for or against: was Democritus' atomism restricted to physics or did it include mathematics? Gregory Vlastos, one of the main supporters of a 'restricted' atomism by Democritus, bases his claim on an essential argument: there is no trace of any 'mathematical atomism' in ancient Greek mathematics.

'If there were such a mathematical system, or even fragments of it, why is there not a word about [Democritus'] mathematics in our sources? I am not asking here for philosophical opinions, speculations, or perplexities concerning mathematical indivisibles, but for some work in mathematics, something like a construction or a proof. Do we know of even a single item of this kind? Democritus' famous fragment on the cone is nothing of the sort. In the first place, this is not work in mathematics, but philosophical reflection on its foundations. In the second place, there is not a word in its text which asserts or implies mathematical atomism or shows that its author is even favorable to mathematical atomism'. ${ }^{60}$

Vlastos' above arguments, as well as many others in the same article, appear strong and well founded. However, his conclusion is based on the very premise that Democritus was a mathematician, or at least that his expertise in mathematics would play an important role in his doctrine. It can be summarized in the following syllogistic form:

1. Democritus was a mathematician

2. A 'mathematical atomism' is inconsistent with mathematics

3. Thus Democritus was not a 'mathematical atomist'.

But there is a catch. That Democritus was a mathematician is highly conjectural, and there is no testimony capable of establishing either alternative. ${ }^{61}$ So let us now consider the following question.

\section{b) Aristotle's testimony}

However, when opposing the methods of atomists and Platonists, Aristotle emphasizes that 'One might observe also from the following considerations how great the difference is between those who investigate in the sensible world and those who remain on the theoretical level'. ${ }^{62}$ For, while some Platonists ${ }^{63}$ would argue that there must be atomic magnitudes ${ }^{64}$ 'because otherwise the "Triangle" ${ }^{65}$ will be more than one', Democritus would 'have been convinced by

(...) Plato, of course, ignores him throughout his dialogues (...); Aristotle, on the other hand, pays handsome tribute to his genius' (Heath (1921), p. 176).

${ }^{58}$ This is Aristotle's very criticism against this theory, which is 'necessarily in conflict with mathematical science' (On the Heavens III, 3, 303a20-23, cf. I, 5, 271b10-11).

${ }^{59}$ Although some authors, on the contrary, consider that Aristotle showed great respect for Democritus. Thus Vlastos speaks of the former's 'rare respect' for the latter (Vlastos (1965), p. 296); cf. also supra, note 57.

${ }^{60}$ Vlastos (1965), p. 293; the author's emphasis.

${ }^{61}$ Heath first claimed explicitly that 'Democritus was too good a mathematician to have anything to do with such a theory [the 'ö́topor $\gamma \rho \alpha \mu \mu \alpha$ '' or 'indivisible lines'] (Heath (1921), p. 181). However, he later seemed to recognize that this was not a sound argument (Heath (1949), p. 79-80).

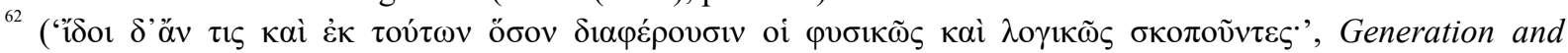
Corruption I, 2, 316a10-11; our translation).

${ }^{63}$ Maybe Xenocrates, who is the target of the treatise On Indivisible Lines.

${ }^{64}$ About this claim, cf. infra, §IV.1.

${ }^{65}$ The meaning here is probably the intelligible Platonic Form of the geometrical triangle. 
arguments appropriate to that is relative to the sensible world' ${ }^{66}$ However, astronomers already knew at that time that the earth had the form of a sphere: indeed, for a contemporary of Democritus with some good knowledge of astronomy, as Plato depicts Timaeus, ${ }^{67}$ this left no room for doubt (Timaeus, 40b-c, 62d ff.). Already in the Phaedo, Socrates claims that he was convinced by an anonymous figure, ${ }^{68}$ of the rotundity of the Earth $(108 \mathrm{e}-109 \mathrm{a} ; 110 \mathrm{~b} 5 \mathrm{ff}$.), warmly approved by his interlocutor (109a8). Hence, it is highly unlikely that a mathematician would ignore, even less go against, astronomical evidences of the sphericity of the earth. ${ }^{69}$

Notwithstanding, this conflates with Aristotle's other claim about Democritus' 'natural' inquiries, as opposed to Platonists' 'verbal' ones. Aristotle is obviously polemicizing here against the Platonists' blind trust in their first principles which are linked to mathematics. ${ }^{70} \mathrm{He}$ is criticizing reasoning based on theoretical arguments, and speaking in favor of those that are based on concrete phenomena, i.e. sensible appearances. ${ }^{71}$ Hence, according to Aristotle, the atomists supposedly changed their theory, rather than be contradicted by the phenomena. This does not entail they followed or even made use of-contemperary the latest scientific theories of their times, but more probably that they made their own explanations as 'concrete' as possible, i.e. as far as possible from any geometrical construction. ${ }^{72}$ Indeed, Aristotle reported a couple of lines earlier that both Leucippus and Democritus 'thought that the truth lays in the phenomena'. ${ }^{73}$ Again, while this would be bizarre in the case of people for whom mathematics matters, even more for mathematicians, it should be expected from those who were exclusively or mainly interested in sensible phenomena. ${ }^{74}$ In this context, the shape of the earth as a drum or a disk makes sense, as does Lucretius' procedure of collecting common sense arguments against a spherical earth in his poem. ${ }^{75}$

\section{c) Democritus and 'mathematical atomism'}

\footnotetext{
${ }^{66}$ I, 2, 316a13-14; our translation.

${ }^{67}$ This is not to take a stand for or against the historicity of the figure of Timaeus, but concerns the character as described in Plato's dialogue.

${ }^{68}$ 'There are many strange places upon the earth, and the earth itself is not such as those who are used to discourse

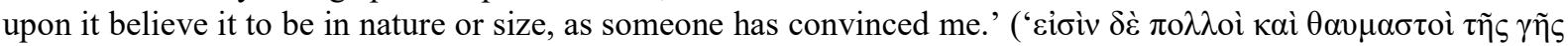

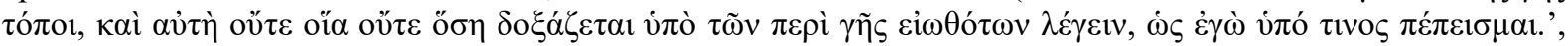
108c5-8).

${ }^{69}$ Aristotle, On the Heavens II, 11, 291b22-23; 14, 297a21-298a20.

${ }^{70}$ On the validity of this claim, see for instance Cleary (1995), p. 112-113.

${ }^{71}$ In other words, he is praising some form of empiricism against mathematics. His previous opposition between 'those who have lived in a more intimate communion with the phenomena of nature' and 'those, on the other hand, who indulge in long discussions without taking the facts into account are more easily detected as men of narrow views' (transl. by E. Forster) (On Generation and Corruption I, 2, 316a6-11) could be understood in this way. David Sedley concludes from this passage that Democritus is indeed presented as a physicist whose attention is devoted to 'empirical fact' (Sedley (2004), p. 86).

${ }^{72}$ When Aristotle himself disputes the claim that the earth is flat, he does not consider truly astronomical arguments but opposes his doctrinal principles to those of his adversaries (On the Heavens II, 13, 294b22-295b9). He proceeds in the same way, when he criticizes Anaxagoras' argument for an earth at rest, in the next paragraph.

73 ' $\dot{\pi} \pi \varepsilon \dot{~} \delta$ ' On the Generation of Animals (V, 8, 789b2 = DK 68 A $66=$ LM 27 D 74), Pierre-Marie Morel notes: 'Aristotle considers Democritus as a physicist who "forget to speak of the final cause and reduces all the means used by nature to necessity" (Morel (2000), p. 9; our translation), as well as (quoting Metaphysics A, 4, 985b19-20= DK 67 A $6=$ LM 27 D 31) the efficient cause (p. 24).

${ }^{74}$ This does not mean that, for Aristotle, it is the right way to study the universe, but a polemical approach to show that even such a primitive interpretation is better and more fruitful than the dogmatism imputed to the Platonists.

${ }^{75}$ Cf. supra, $\S 1$.
} 
Guthrie summarizes the problem, and concludes, on the basis of Aristotle's testimony, ${ }^{76}$ that Democritus' 'physical' atomism needed the support of a 'mathematical atomism'. " Similarly, after studying Aristotle's texts on Democritus, in particular Generation and Corruption, A2, David Furley concludes that to try to differentiate 'physical or theoretical division of bodies' leads to 'too many paradoxes here. It seems much simpler to believe that neither Democritus nor Aristotle made any distinction between physical and theoretical divisibility (...) Democritus thought of his indivisible magnitudes as being theoretically as well as physically indivisible.' ${ }^{78}$ Finally, Marcel Conche defines the basic geometrical notions of 'mathematical atomism' as follows: 'the point would be a small cube with side of minimal length, the line a kind of an elongated parallelepiped, etc. ${ }^{79}$ Volumes would consist in a very large but finite number of elementary thin volumes that are mathematically indivisible'. ${ }^{80}$ This entails the reduction of all mathematics to arithmetic, so that it can be expected to be supported by philosophers for doctrinal reasons rather than by mathematicians, and, according to Aristotle's texts, ${ }^{81}$ a good candidate would be Democritus. Hence, Jean Salem can claim that 'in mathematics, Democritus erred by excess of empiricism', ${ }^{82}$ to conclude that 'Democritus degraded this entire subject area [mathematics] to a subpart of physics, and therefore, he seems to have reduced the field of pure mathematics to that of arithmetic'. ${ }^{83}$ And indeed, since 'mathematical atomism' entails the existence of minimal spatial figures in geometry of any dimension (i.e. surfaces or lines). If these conclusions are right, Democritus was certainly not a mathematician. He was primarily interested in natural phenomena, for then, without inconsistency, he may have considered the 3-dimensional space along the lines of Conche's presentation. ${ }^{84}$

Thus, if our analysis is right, the previous 'syllogism' of Vlastos:

Democritus was a mathematician/A 'mathematical atomism' is inconsistent with mathematics/Thus Democritus was not a 'mathematical atomist',

needs to be changed into:

'Mathematical atomism' is inconsistent with mathematics/ Democritus was a 'mathematical atomist'/Hence, Democritus was not a mathematician,

\footnotetext{
${ }^{76}$ On Generation and Corruption, especially 316a 14ff (cf. Guthrie (1965), p. 396).

77 'Democritus held, and was prepared to argue, that his atoms, being not only very small but the smallest possible particles of matter, were not only too small to be divided physically but also logically indivisible. To suppose otherwise would admit the principle of infinite divisibility, which to Democritus was inconceivable.' (Guthrie (1965), p. 396).

${ }^{78}$ Furley (1967), p. 93-94.

${ }^{79}$ Taking exactly the same line of argumentation, these strange features of such a mathematics based on 'atoms' is, according to him, the strongest argument for rejecting the existence of any theory of 'mathematical atomism' among ancient Greek mathematicians (Vlastos (1965), p. 292).

${ }^{80}$ Conche (2011), p. 452, our translation. He draws on earlier scholars as S. Luria (Luria (1932), p. 106 f.) and J. Mau (Mau (1954)). A similar point is supported by P.-M. Morel, who holds that points in geometry are replaced by small 'polyhedrons of all shapes' (Morel (2000), p. 40).

${ }^{81}$ Cf. supra, a), in particular note 58.

${ }^{82}$ 'en mathématiques, il semble avoir péché par excès d'empirisme' (Salem (1997), p. 50).

${ }^{83}$ 'Démocrite a ravalé cette dernière discipline [la mathématique] au rang de sous-partie de la physique et il semble, par conséquent, avoir réduit le domaine de la mathématique pure à celui de la seule arithmétique.' (Salem (1997), p. 51). Cf. also Hahm (1972), p. 206, n. 3; Berryman (2016), §2. Although such conclusions seem reasonable and supported currently by most scholars, there is no unanimity (Guthrie (1965), p. 485). For a contrary position, cf. Burnet (1892), p. 336; Vlastos (1965), p. 125 ff. (and also, supra, §ii).a)); Barnes (1979), p. 273. Stephen Makin goes so far as to claim that an atom is, for Leucippus or Democritus, 'an extended body with parts', arguing that it does not have any kind of indivisibility (Makin (1989), in particular p. 148-149).

${ }^{84}$ Although these atoms may have other forms, for instance instead of a cube a point could be a tiny sphere.

${ }^{85}$ Cf. supra, §a).
} 
so that Vlastos' very argumentation entails the opposite of his conclusion.

\section{iii) Democritus and Cavalieri}

To complete the study of the possible meanings of 'mathematical atomism', let us consider briefly a much later theory linked sometimes to Democritus. It matters to dispel any claim of the use of the infinite in Timaeus' construction of the elementary particles composing the universe. It is Cavalieri's theory of the 'indivisibles', which is also linked to a primitive theory of integral calculus, going back to the works of Archimedes.

Cavalieri's 'indivisibles' is the first detailed mathematical theory making explicit use of 'indivisible lines' or 'indivisible surfaces'. Geometrical surfaces are infinite sums of parallel lines that can be treated, in some way, as finite sums. ${ }^{86}$ Since these lines compose a complete surface, they need to be 'indivisible' in width, for otherwise it would be possible to add other lines between the first ones, and the surface composed by the first lines would be incomplete. However, as it was largely known well-before Cavalieri's times, geometrical lines are supposed to have no width, so how can their width be indivisible? Moreover, how can an addition of lines without width form a surface with some width? This opens the door to the many paradoxes of infinity, ${ }^{87}$ that were debated by mathematicians of the $17^{\text {th }}$ century. Let us briefly consider both how the 'indivisible' lines were used and the problems they generate. ${ }^{88}$
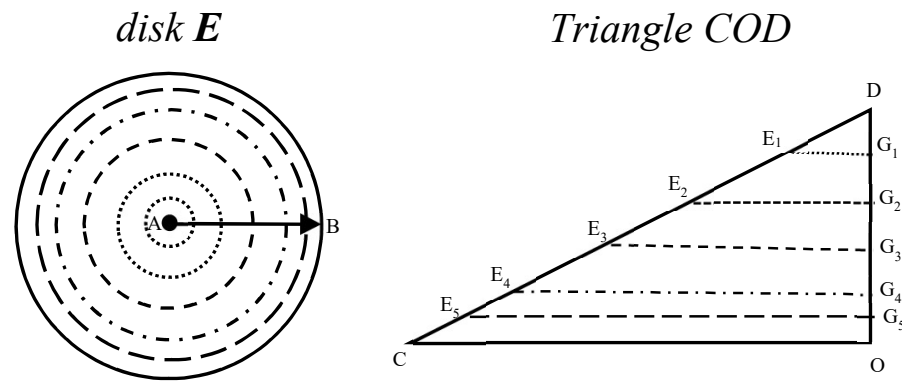

Figure 4

The above figure illustrates an application of Cavalieri's theory: to compute the surface of a disk $\boldsymbol{E}$, knowing that the circumference is proportional to the radius. ${ }^{89}$ Let COD be a right triangle of base $\mathrm{CO}$ equal to the circumference of $\boldsymbol{E}$ and of side OD equal to the radius $\mathrm{AB}$ of $\boldsymbol{E}$. Since the circumference is proportional to the radius, to any circle inside the disk $\boldsymbol{E}$ there corresponds, in the triangle COD, one and only one straight line of length the perimeter of this circle (i.e. $\mathrm{E}_{1} \mathrm{G}_{1}, \mathrm{E}_{2} \mathrm{G}_{2}, \mathrm{E}_{3} \mathrm{G}_{3}, \ldots$ ). Hence, since a disk is the sum of all the circumferences inside it, and a triangle is the sum of all the lines inside it, ${ }^{90}$ the area of the disk $\boldsymbol{E}$ and the area of the triangle $\mathrm{COD}$ are equal. The latter is equal to $1 / 2(\mathrm{CO} \times \mathrm{OD})$, which is also half the product of the circumference of $\boldsymbol{E}$ by its radius. ${ }^{91}$

\footnotetext{
${ }^{86}$ And similarly for volumes, where the 'indivisible lines' would be replaced by 'indivisible surfaces'.

${ }^{87}$ This may explain Galilei's reservation towards Cavalieri’s indivisibles (cf. supra, note 91).

${ }^{88}$ Cf. infra, Figure 5. Quoting Cavalieri (1647), p. 241, Boyer notes that for the former, 'Rigor was the affair of philosophy rather than geometry’ (Boyer (1949), p. 123). See also Boyer (1968), p. 88-89; Smith (1976), p. 585.

${ }^{89}$ In modern terms, the perimeter of a circle of radius $R$ is equal to $2 \pi R$.

${ }^{90}$ Here the 'indivisibility' (of the width) of the lines is needed.

${ }^{91}$ In modern terms, its area is equal to $1 / 2(2 \pi R) \times R=\pi R^{2}$. Cavalieri was extremely cautious with his method, and in a letter to Galilei, he wrote: 'Namely, I absolutely do not declare to compose the continuum by indivisibles.' (Galilei, vol. 18, p. 138; quoted in Andersen (1985), p. 307). Cf. Cavalieri (1635), theorem VI.2.6; Cavalieri (1632), p. 160-161; and for more details on this construction, see Blay-Egidio (1998), p. 76-82. Many mathematicians made some use of indivisibles in this period, for instance, Kepler (cf. Kepler (1858)), Roberval
} 
However, there is a caveat, and it is easy to obtain wrong results, as shown in the figure below.



Figure 5

Let $\mathrm{ABC}$ be a non-isosceles triangle and $\mathrm{HB}$ its height from the edge $\mathrm{B}$ to the side $\mathrm{AC}$. There is clearly a one-to-one correspondence between equal lines in the triangles $\mathrm{BHA}$ and $\mathrm{CHB}$, as seen above between $A_{1} B_{1}$ and $H_{1} C_{1}, A_{2} B_{2}$ and $H_{2} C_{2}, A_{3} B_{3}$ and $H_{3} C_{3}, \ldots$, respectively. However, the areas of the triangles $\mathrm{BHA}$ and $\mathrm{CHB}$ are obviously unequal. ${ }^{92}$

No trace of such a process is found in Greek mathematics, where the difficulties in dealing with the infinite were well known even at an early stage, as shown by Zeno's paradoxes. ${ }^{93}$

Hence, we can safely conclude that, previously to Plato and Socrates, there were probably supporters of 'mathematical atomism', and that Democritus was one of them. Moreover, this 'mathematical atomism' has nothing to do with the composition of figure by an infinite number of parts of one dimension less, that is in the sense of Cavalieri's 'indivisibles'. As surprising as it may appear to us, a reason of its rejection by some scholars, it is based on the existence of minimal parts for any geometrical object, that is any line is a compound of lines of minimal lengths, any surface of surfaces of minimal area, and any body of bodies of minimal volumes. For the Timaeus, our analysis leads to the following conclusion: at the dramatic date of the Dialogue, there was indeed a theory which may be qualified as 'mathematical atomism' (though it was not in Antiquity), having its origins in Democritus' philosophy and closely connected to his philosophical atomism.

\section{Plato vs 'mathematical atomism'}

However, this 'mathematical atomism' entails the strangest kind of geometry, requiring the existence of atoms in mathematics, that is of minimal, atomic (indivisible) magnitudes. ${ }^{94}$ According to Aristotle testimony, it seems that it was already difficult in Antiquity to accept such a theory, which would ruin the principles of mathematics, the most exact science for ancient Greeks, ${ }^{95}$ and that it was easy to show the falsehood of such a theory. ${ }^{96}$

(Roberval (1693), English translation in Walker (1932)), Pascal (in particular, his Traité des sinus). Though Cavalieri seems to have been held in high regard by Galilei (cf. Andersen (1985), p. 294), the latter was ambiguous regarding Cavalieri's theory of the indivisibles (ibid., p. 353).

${ }^{92}$ This counter-example is given by Cavalieri himself. He claims that it was sent to him by an anonymous writer (see Andersen (1985), p. 309)

${ }^{93}$ See Aristotle's Physics, VI, 9, 239b5-240a20; as well as Simplicius' Commentary on Aristotle's Physics, 140.29. See also Aristotle's claim on the possibility of dispensing with the infinite in mathematics (Physics, III, 11, 207b27-34).

${ }^{94}$ As claimed in the Treatise On Indivisible lines, this conception was indeed supported in Antiquity. Indeed, the book begins with the words: 'Are there such things as indivisible lines, and must there be in all magnitudes some

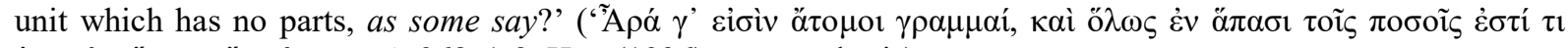



${ }^{95}$ On the Heavens, I, 5, 272b9-11.

${ }^{96}$ Physics, III, 6, 206a17. 


\section{Plato and 'indivisible lines'}

The attribution of a conception of 'atomic' or 'indivisible' figures to Plato is rooted in the one and only text by Aristotle which claims that: '

Plato objected to this kind [the points] as rooted in an assumption of geometers, and he called the indivisibles lines the principle of the line, and this he did very often. ${ }^{97}$

This sentence is the only one linking directly Plato to indivisible lines. ${ }^{98}$ Its understanding was certainly easier for Aristotle's audience and readers, who had in mind the necessary Platonic background. An indirect testimony is found in a pseudo-Aristotelian treatise: On indivisible lines. ${ }^{99}$ However, both Aristotle's sentence and the treatise are difficult to interpret, and there is much disagreement among the scholars about them (cf. infra, note 100).

\section{i) The treatise On indivisible lines}

The text of the treatise is, moreover, extremely problematic. It is unintelligible in its original form and 'needs corrections everywhere', so that there are as many different interpretations as different commentators. ${ }^{100}$ Neverteless, some points are clear. It begins by asking whether such 'atomic lines (' $\alpha \tilde{\tau} \tau \mu \mu \mathrm{or} \gamma \rho \alpha \mu \mu \alpha$ ')' exist, to show that the hypothesis of atomic lines is inconsistent with principles in mathematics that no one should refute. ${ }^{101}$ Indeed, as seen in $\S$ III.c), supra, to admit indivisible lines of finite length 'conflicts with nearly everything in mathematics. ${ }^{102}$ Since it was written against the Platonists or even Plato, there is a difficulty as summarized by Allen. According to the scholar, the alternative is as follows: either the people of the Academy supported an absurd theory or that they had some (primitive) theory of infinitesimals. And since the latter 'were not geometrical illiterates and understood the fact of incommensurability', the second part of the alternative is true. ${ }^{103}$ In other terms, the solution is to admit an anachronistic kind of mathematics in the $4^{\text {th }}$ century BCE, similar to the anachronistic claim that Democritus had some primitive anticipating Cavalieri's one (cf. supra, §III.2.iii).

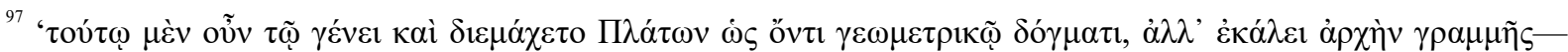


'that Plato denied the existence of the point and asserted that of indivisible lines is not directly stated elsewhere, but the same views are ascribed to Xenocrates, and were attacked in the treatise De lineis insecabilibus' (Tredennick (1933), note 5 at 992).

${ }_{98}$ 'We have no further direct information about Plato's rejection of the point and assertion that there are indivisible lines.' However, this doctrine is usually ascribed to Xenocrates (Ross (1924), n. 20, p. 203).

99 'ПЕРI АТОМ $\Omega$ N ГРАММ $\Omega$ N'. Almost all scholars agree that the treatise is not from Aristotle (cf. for instance, the introduction in Hett (1936))

${ }^{100}$ Michel Federspiel writes that 'The treatise On Indivisible Lines is the one that has the most suffered in the Aristotelian corpus, along its transmission, obviously because both of its subject and of its style. Thus, the text of the manuscript needs corrections everywhere. Its lost archetype included already many mistakes, as shown by D. Harlfinger in his study on the history of the text of the treatise.' (Federspiel (1981), p. 502). In another article, he complains that 'it would be too long to examine the different versions and interpretations imagined by every editor and translator.' (Federspiel (1992), p. 45), while on the previous page, he remarks that 'it is impossible to translate this text in its actual form' (ibid., p. 44), because taken literally, it is incoherent.

${ }^{101}$ 'It is clear that the author [of the treatise] wants to refute the theory of indivisible lines by showing it is incompatible with a geometrical procedure [the dichotomies] accepted by everyone, and the supporters of indivisible lines are also supposed to accept.' (Federspiel (1992), p. 45). See also the previous paragraph, supra.

${ }^{102}$ Allen (1983), p. 293; also Aristotle's On the Heavens, 299a5-10.

${ }^{103}$ 'it is a reasonable inference that if anyone in the Academy maintained a doctrine of indivisible lines, those lines must have been not merely "mighty small," but infinitely small, minimal or infinitesimal parts conceived as indivisible on the ground, presumably, that what is infinitely small admits no smaller. Minimal parts, so conceived, would not measure a magnitude' (Allen (1983), p. 293; cf. On Indivisible lines, 969b-970b).
} 
Before him, Taylor reached the same conclusion, writing that Plato and/or the Platonist were 'on the track' toward such a theory of infinitesimals (Taylor (1926), p. 506). Unfortunately, besides the anachronistic character of Taylor's conclusion, this would be consistent with Cavalieri's 'indivisible lines', but not with the meaning in accord with atomism (ancient or modern), which considers that any object is made up of a finite number of atoms. ${ }^{104} \mathrm{Hence}$, if Allen's alternative is correct, the reasonable conclusion is that some ancient Greek philosophers, ${ }^{105}$ even in the Academy, endorsed such a geometrically 'unreasonable' theory, and were blamed for this by Aristotle, as done by some later atomists, including Epicurus himself (cf. supra, III.1). The main argument supporting this interpretation is the very existence of the 'On indivisible lines', for it would be absurd to devote an entire treatise against some non-existing theory. ${ }^{106}$

\section{ii) Aristotle's sentence (Metaphysics, A, 9, 992a20-22)}

There are also different interpretations of this cryptic passage. ${ }^{107}$ Nevertheless, the most reasonable seems to be the one proposed by A. E. Taylor, that Plato is refuting the reduction of mathematics to arithmetic, as well as the representation of the unit by a point, ${ }^{108}$ a flawed conception assigned by Taylor to the Pythagoreans. ${ }^{109}$ Instead, the unit must have a geometrical representation by a line, which entails that this line being indivisible as any unit.

Let us also recall that Socrates in the Republic notes that the mathematician laughs at the ignorant who would divide the unit, multiplying it immediately (VII, 525d8-e4). A representation of the unit by a point would be inconsistent, since it is not only impossible to divide it, but also to multiply it, the usual representation of a number by juxtaposition being criticized by Socrates in several dialogues (Phaedo 101b4-c9, Theaetetus 155a2-c10; cf. also Aristotle's Metaphysics M, 7, 1080a-b). This passage may be read in connection to a text of Aristotle in the Metaphysics:

Each question will be best investigated in this way by setting up by an act of separation what is not separate, as the arithmetician and the geometer do. For a man qua man is one indivisible thing; and the arithmetician supposed one indivisible thing, and then considered whether any attribute belongs to a man qua indivisible.' (M, 3, 1078a21-25). Then, Aristotle adds that 'the geometer treats him neither qua man nor qua indivisible, but as a solid.' (a25-26).

\footnotetext{
${ }^{104}$ Joachim (1908), 968a2, note 1, quoted in the introduction section III.

${ }^{105}$ As seen previously, this is the case for later atomists, including Epicurus (cf. supra, §III.1).

${ }^{106}$ It is why some prominent commentators of Aristotle as David Ross claim that at Plato's time 'various thinkers had believed in indivisible lines, and Plato's' among them (Ross (1924), p. 204), and Thomas Heath agrees with him (Heath (1949), p. 199). It is not clear whether this property has to be restricted to the 'ideal' line, or concerns also the geometrical line (Ross (1924), p. 205), though the latter is an unreasonable assessment for any serious reader of Plato's dialogues (cf. infra, note 111). This an example of the consequence when one trusts blindly Aristotle about Plato, a mistake already emphasized by Harold Cherniss (for instance, Cherniss (1944), p. 121).

107 'a vexed question' according to Heath (1949), p. 199. In his commentary of the Metaphysics, it takes no less than six pages of notes for Ross to explain this passage (Ross (1924), p. 202-208). For the different interpretations, see also Heath (1949), p. 199-200, Taylor (1926), p. 505-507) and the translations and/or notes on this passage in the translations of the Metaphysics by David Ross (in the The Works of Aristotle, Oxford Univ. Press, 1928), Hugh Tredennick (Harvard Univ. Press, 1933), Jonathan Barnes (in The Complete Works of Aristotle, Springer, 1996), Jules Tricot (Vrin, 1953, in French) and so on; cf. also supra, note 98).

108 'This means, of course, that Plato rejected the conception of a point as a minimum of volume, or "unit". It has no magnitude of its own but is "the beginning" of the straight line which has such a magnitude (its length). In other words, what corresponds in arithmetic to the point is not 1 but 0 , if only Greek arithmeticians had possessed a word or symbol for 0.' (Taylor (1926), p. 506).

${ }^{109}$ 'In the Pythagorean mathematics of the fifth century there were two serious logical flaws. One was that in treating geometry as an application of arithmetic, the Pythagoreans had made the point correspond to the number 1 , as is indicated in the traditional definition of the point often mentioned by Aristotle, that it is $\mu$ ovòs है $\chi 0 v \sigma \alpha$




Thus, the same may be considered either as indivisible or divisible. This is close from the above quotation in the Republic: as representing the arithmetical unit, the latter is indivisible; as a geometrical object, it is indefinitely divisible. The geometer laughs when the geometry-illiterate confuse the two notions.

Hence, it is reasonable to consider with Taylor that the foregoing passage (A, 9, 992a20-22) means that, Plato in his lectures, or in some discussions in the Academy, considered that the unit must be represented not by points but by lines, as it will be in Euclid's Elements, that is a representation of arithmetical objects by geometrical ones. This entails that the same object may belong to several different fields, here arithmetic and geometry. Then, according to this filed, it may have different properties, here absolutely indivisibility or at the contrary in(de)finitely divisibility. In other terms Plato considers there are bridges between different fields. Thus, Aristotle's sentence may be understood as a criticism of Plato who, unlike the former, did not consider the need of a radical separation between arithmetic and geometry. ${ }^{110}$ As a matter of fact, there is no known text of Plato in which he would have claimed the existence of atomic lines in geometry. Namely it appears so inconsistent with all Plato's dialogues that D. Sedley could simply write concerning Plato's postulation of indivisibles, 'surely Plato didn't do that'. 111

\section{The 'atomic' triangles}

\section{i) The basic triangles in the Timaeus}

Notwithstanding, Plato's Timaeus itself makes use of some smallest surfaces, two basic right triangles: one isosceles, the other half-equilateral. Though, it is never said they are 'indivisible', it seems to be a fair consequence of their minimal sizes: since there are no smaller triangles, if they were not indivisible, it would be possible to divide each of these two triangles into two triangles of the same kind, i.e. either two isosceles right triangles or two half-equilateral triangles. They constitute the faces of the four regular polyhedrons forming the four elements in Timaeus' universe (fire, air, water, earth).
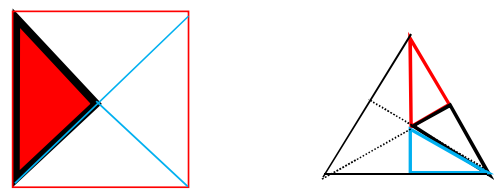

Figure 6

The figure on the left shows how, according to-TheaetetusTimaeus, four isosceles right triangles produce a square, the faces of the smallest cubic particles of element earth. The figure on the right shows the construction of an equilateral triangle from six half-equilateral triangles; equilateral triangles constitute the faces of three regular polyhedrons, the tetrahedron, the octahedron and the icosahedron, which are respectively the forms of the smallest particles of the three other elements: fire, air and water $(54 \mathrm{~d}-\mathrm{e})$. Hence, these two basic right triangles are the minimal components of the faces of all the particles ${ }^{112}$ forming Timaeus' universe. Added to some misreading of Aristotle text considered in the previous paragraph, some modern scholars claim that these triangles may be characterized as 'mathematical or geometrical atoms'. Thus, they can add that Timaeus' cosmology is a 'mathematical atomism'. So let us consider their arguments.

\footnotetext{
${ }^{110}$ On this passage, Jules Tricot refers, in his translation of Metaphysics, to the incommunicability between the genera' in Posterior Analytics, I, 7; cf. also for instance, Politis (2004), p. 308.

${ }^{111}$ Sedley (2008), p. 308; the author's emphasis.

${ }^{112}$ These basic right triangles are not particles, not even the plane faces of such particles, but the parts forming the faces of these particles.
} 


\section{ii) Atoms against continuum}

In which way can these triangles be said 'atoms'? Certainly not as the ones of the atomists, since adding a finite number, how large it may be, of such triangles, will never give a spatial body. Since it was shown that it is unreasonable to consider that Timaeus ever considered an infinite number of such triangles (the 'indivisibles' à la Cavalieri), it seems that its meaning would be restricted to its etymology. Hence, for these commentators, Timaeus' triangles are 'atoms' because they are 'a-tomic' that is indivisible. According to theses scholars, on the one hand, there is Aristotle's matter that is a continuum i.e. is indefinitely divisible, on the other hand, the Timaeus proposes a construction from triangles. This is based on Aristotle's authority given by two texts quoted previously. ${ }^{113}$ A paradigmatic example is given in the following statement of John Cleary, quoted thereafter:

In the case of Plato also, we find a similar choice about the basic structure of matter being made in the Timaeus, where he parts company with the Atomists on the question of infinity, while accepting their conception of matter as discrete rather than as continuous. By contrast with Aristotle who treats matter as a continuum, Plato sees it as being constituted from basic triangles as discrete units, although these are regular in shape and finite in number, unlike the irregular infinity of atoms. If matter were left to its own devices, Plato seems to say, it might behave in a random and mechanical fashion, but that would not explain the order of the visible cosmos. (Cleary (2013), p. 223; our emphasis).

An obvious problem with this argumentation is that it identifies Timaeus' khora to the matter or the space, ${ }^{114}$ depending on how one understands that matter is in the khora or is the khora. ${ }^{115}$ Since the Aristotelian term of 'matter' ('hylê') is used only once in the Timaeus, and not in the sense of 'matter', ${ }^{116}$ we avoid this term. Cleary opposes Aristotle's and Plato's cosmologies through the opposition of the continuum (Aristotle) and the discrete (Plato). But this is made possible by a confusion that goes back to Aristotle. For Timaeus, all bodies are indeed composed of particles of the four elements, and each of these particles is one of four regular polyhedrons: the cube, the icosahedron, the octahedron and the tetrahedron. However, is it possible to claim that 'matter' is constituted by 'basic triangles' for Plato? This is certainly not clear. As remarked above, it cannot mean that matter (i.e. particles forming 'sensible bodies') is a (infinite) addition of triangles, since this would entail a construction similar to the one of Cavalieri's for whom 3-dimensional figures are composed from an infinite number of respectively 2-dimensional triangle. As it was shown in §III.iii), supra, such a construction, was not an acceptable method by the Greeks in the $5^{\text {th }}-4^{\text {th }}$ century BCE (or in Antiquity). ${ }^{11}$

While the four regular polyhedrons, hence the elementary particles, are constructed out of

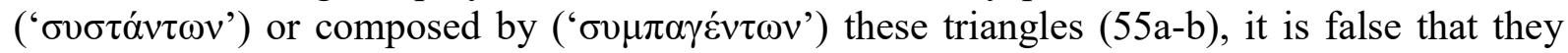
compose bodies directly. Namely, Cleary, as many other commentators, forgets an essential intermediary state of the formation of elementary particles: some identical triangles must associate together to form a solid angle, and only then, the particles are composed by several of such angles (54e $3 \mathrm{ff}$.). Hence, while it is possible to oppose Aristotle continuous matter to Timaeus' discrete bodies as constituted by polyhedral particles, it is plainly wrong to oppose

\footnotetext{
${ }^{113}$ Generation and corruption, 325b27-29; On the Heavens, V, 2, 308, b30-32 (cf. supra, notes 17 and 18); cf. also supra, §1.i).

${ }^{114}$ Cf. Miller (2003), p. 19.

115 'a much-discussed question' (Zeyl (2010), p. 118). A little later Cleary admits that the khora cannot be 'a material substratum like Aristotle's prime matter'; for the hesitation between the different possibilities, cf. Cleary (2013), p. 225; cf. also, Zeyl (2010), p. 118-119.

${ }^{116}$ Against the assimilation of khorra to (Aristotelian) matter, cf. Zeyl (2010), p. 118. Let us remark that the notion of 'matter' in Aristotelian sense is not so clear; cf. for instance the article of William Charlton about Aristotle's 'prime matter' (Charlton (1983)), and the sources that he quotes and discusses.

${ }^{117}$ And Aristotle's criticism is precisely that 'bodies (...) are not constituted from planes.' (Cleray (1995), p. 73).
} 
the continuous matter to the triangles. Aristotle's matter is not composed by geometrical figures, and certainly not by surfaces, for it is one of his main criticisms against Plato's cosmology. ${ }^{118}$ Moreover, this supposes a hypothesis not only absent in the Timaeus, but inconsistent with it. Aristotelian matter is an abstraction opposed to another Aristotelian abstraction, the form (in the common sense), and neither exists independently from each other. ${ }^{119}$ On the other hand, Timaeus' particles are regular polyhedrons, that is, even from the framework of Aristotle's point of view, they exist and have geometrical forms. Once again, the alleged 'atomism' of the Timaeus leads to a confusion where triangles and polyhedrons are intermingled.

\section{iii) The puzzle of Timaeus' basic triangles}

Nevertheless, Timaeus' construction poses a real problem, the one the treatise On the indivisible lines seems to highlight. On the one hand, elementary particles are built from the composition of mathematical triangles, as made clear in the dialogue and by Aristotle's' criticism of the dialogue. On the other hand, there are smallest triangles forming the faces of the smallest particles of each of the four elements, all other elementary particles are formed from triangles that are composed by theses smallest triangles. ${ }^{120}$ However, as seen previously, such 'atomic' figures are inconsistent with almost all mathematics, in particular geometry. ${ }^{121}$ Plato's proficiency in this field, as demonstrated in many dialogues, not the least of which is the Timaeus, entails would be unreasonable to suppose he may ever have agreed to such hypothetical 'atomic' triangles. Thus, how to explain the seemingly inconsistency with Timaeus' construction of elementary particles? A reasonable answer lies in the nature of the khôra, the third genus which allows the existence of the continuously coming and passing away of elementary regular polyhedral particles. As Timaeus told us, the khora, a puzzling third genus, can be known neither by the sense nor by the intellect, but only by some bastard reasoning as in a dream (52b2). Hence, the only reasonable explanation that the mathematical triangles, isosceles or half-equilateral, in the khora has some minimal sides, is it is a consequence of the almost impossible to know nature of the khorra, not the nature of the mathematical triangles. Hence, while the nature of the khôra is 'difficult and obscure', ${ }^{122}$ we can nevertheless say that it is an intermediary between the model of the intelligible forms and the sensible bodies, containing isosceles and half-equilateral right triangles, which when it is possible, will compose together, to then form one of the four regular polyhedrons, tetrahedron, octahedron, icosahedron and cubes, i.e. one particle of one of the four elements. The how and why are not even touched upon by Timaeus; maybe it is too long or too difficult, or even it has to be left to the gods and the ones they like (53d5-6). Either way, Timaeus is justified to speak about a khôra as seen as in a dream. Its existence does not follow from any testimony either from the senses or from the intellect $(52 \mathrm{~b} 1-2)$, but from the existence of two kinds of 'knowledge', the opinion and the science. This entails the existence of two genera, one of the sensible things continuously changing, the other of the intelligible forms eternal and immutable. Nevertheless, both genera are not disjoint, since the former is to the latter as its model (52a47). Hence, the need of an intermediary to connect both genera. Hence, the existence of a third

\footnotetext{
${ }^{118}$ On the Heaven, 268b1-6; cf. also the analysis of John Cleary, in Cleary (1995), p. 73-74.

${ }^{119}$ For instance, Physics, IV, 2, b22-23.

${ }^{120}$ The necessary existence, because of the laws of transformation between the four elements, of such smallest triangles from which all triangles are formed to compose the faces of the four regular polyhedrons is wellestablished in Cornford's Commentary of the Timaeus (Cornford (1937), p. 230-232, on 57c-d). Nevertheless, it is possible to disagree with the solution proposed thereafter (p. $232 \mathrm{ff}$.).

${ }^{121}$ Cf. supra, §III.1.

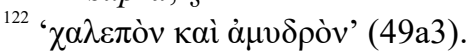


genus, the khora. Nevertheless, the evidences are only indirect, that is why when we consider the latter, it is like we were asleep, and our understanding is blurred. What we can say is that it is where the basic right triangles, isosceles or half-equilateral, may compose the four regular polyhedrons and where these polyhedrons in turn are decomposed into these basic triangles. Their minimal sizes are entailed, as seen above, by the nature not of the triangles but of the khôra; in other words, they are minimal as limits of physical bodies, not as geometrical triangles. ${ }^{123}$ As a matter of fact, nowhere in Plato, it is possible to find any hint about the existence of such 'atomic' triangles in geometry, which, as for the existence of 'atomic' lines, would directly contravene the principles to the mathematics of his time. ${ }^{124}$

Then, once again because of the nature of the khôra, four right isosceles (or six half-equilateral triangles) compose one square (or one equilateral triangle) (cf. supra Figure 6), then adjust respectively to form either some cube or some regular tetrahedron, octahedron or icosahedron, that is some elementary particle. In this sense, the khora can be considered indeed as some sort of nurse of the sensible world (49a6). To the question, what in the nature of the kora entail these properties, Timaeus' answer is that we do not know, because we do not know the nature of the khora, and only the gods or the people liked by them may perhaps have an answer (53d6-7).

The conclusion is that Timaeus' triangles are not mathematical or geometrical as conceived as 'atoms', and they are not atoms when conceived as mathematical or geometrical. Nevertheless, precisely because of the almost impossibility to know its nature, the khora cannot be either the (mathematical) space or the matter in the space (whatever it is). Another more intrinsic reason, it cannot be the first because there is a limit on the size of the isosceles and half-equilateral triangles it contains, and it cannot be the second because the matter in the space (whatever it is) since it contains such mathematical plane triangles. Hence, it is even less possible to be both the space and the matter.

\section{iv) The basic triangles and the principles of the universe}

As a warning against any dangerous atomistic slip, Timaeus suggests that the basic right triangles are not even the ultimate geometrical principles in the composition of the universe. At $53 \mathrm{~d}$, he first claims that it is reasonable to consider the particles of the four elements to be four regular polyhedrons. ${ }^{125}$ Since the faces forming these polyhedrons are squares or equilateral triangles, these particles are all obtained from the assembly of either isosceles basic right triangles (for the element earth), or half-equilateral basic right triangles (for the three other elements). ${ }^{126} \mathrm{He}$ then seems to conclude that the principles of all bodies have been found. ${ }^{12}$ However, he goes on to add that there are more ultimate ones 'known only to the god, and to

\footnotetext{
${ }^{123}$ Cf. infra, note 133. This delicate distinction leads some scholars to refute the existence of minimal triangles in the Timaeus, and to suggest that all the triangles can be indefinitely divided (Bruins (1951), Visintainer (1998)). We study this problem and Cornford's solution in another article.

${ }^{124}$ There is a close connection between atomic lines and atomic triangles. Assuming the existence of atomic lines in Antiquity, in the framework of these mathematics and according of the meaning of 'infinite' or 'unlimited', there would be at most a finite number of such lines of different lengths. Thus, there would be a line of smallest length. Thus, the sides of any triangles could not be less than the length of this smallest line, which entails there would be no triangles smaller than the ones formed by this smallest line. Conversely, if atomic triangles exist, then it would be impossible to draw the heights of these triangles, since the height will form new smaller triangles inside these atomic triangles. Then, the argument that all triangles can be formed from right triangles would be false, in contradiction with Timaeus' claim (53c8-d2). Thus, in the context of the Timaeus, the existence of atomic lines and atomic triangles are more or less equivalent.

${ }^{125}$ Cf. supra, point I.1.d).

${ }^{126} 53 \mathrm{c} 4-\mathrm{d} 4$. Spatial bodies are defined by the surfaces limiting them.

${ }^{127}$ 'This, then, we presume to be the originating principle of fire and of the other bodies, as we pursue our likely account in terms of Necessity.' (53d4-6).
} 
any man he may hold dear.' ${ }^{128}$ David Sedley remarks that 'readers of the Timaeus since Aristotle have regularly understood that the primary triangles are indivisible and indissoluble', that is, they are forgetting the lines 53d6-7. However, drawing on these forgotten lines, Sedley remarks that it is necessary to ask "how indissoluble they are?", ${ }^{129}$ and in a note, he considers Xenocrates' claim that 'the triangles truly [are] primary' as 'extravagant', for Xenocrates would thus be claiming to be either god or 'someone dear to him'. ${ }^{130}$ Hence, even the right triangles that form the faces, squares or equilateral triangles, of the elementary particles are probably not indivisible, although Timaeus seems not to want to delve into the issue. Moreover, the treatise On Indivisible lines argues against atomic planes figures, including triangles, as well as atomic lines, ${ }^{131}$ although the connection between these two notions is not clear. ${ }^{132}$ Timaeus is far from considering the basic right triangles to be atomic that he never bothers to say they are the smallest ones. This has to be deduced from his general account, entailing many divergences among Plato's commentators on how to understand his 2-triangle construction in such a way that it could be consistent with the infinite diversity of nature.

However, one may encounter here a difficulty highlighted by Aristotle. If the triangles were components of the universe as the faces of the elementary particles, the same may be true for the indivisible lines forming the sides of these triangles, and finally the points, as extremities of these lines. Then, the principle of Timaeus' universe would be the points:

In general, the result is either that there is no magnitude at all, or that all magnitude could be done away with. For a point is to a line as a line is to a plane and as a plane is to a body. Now the various forms in passing into one another will each be resolved into its ultimate constituents. It might happen therefore that nothing existed except points, and that there was no body at all. ${ }^{133}$

However, this statement overlooks entirely the active role played by the khora in Timaeus' cosmology, as the khôra is (wrongly) assimilated by Aristotle, either to the physical space, or the abstract matter, or both (Physics, IV, 2), or nothing at all. ${ }^{134}$ Only then, is it possible to conclude that Plato's cosmology is 'unreasonable' (Generation and Corruption I, 2, 315b3233), or even 'contrary to mathematics' (On the Heavens III, 1, 299a4). The same remark is valid against Aristotle objection that the basic triangles may compose triangles instead of polyhedrons (On the Heaves III, 1, 299b25-31).

Whatever the case, this is in complete opposition to the doctrine of atomism, whose basic principle is that all bodies are clusters of eternal and unchanging atoms, one of the few points on which all atomists, ancient and modern, seem to agree.



${ }^{129}$ Sedley (2002), p. 68.

${ }^{130}$ Ibid., note 61 .

${ }^{131}$ Ibid. David Sedley draws a parallel between a world without beginning (against Timaeus' cosmogony) and atomic lines, which would entail that the latter, like the former, was a revision of Platonic doctrine (ibid., p. 69).

${ }^{132}$ The problem is how atomic lines can form atomic triangles. For instance, if $u$ is the atomic line, the only possible right triangles will be of sides forming a Pythagorean triplet (for instance, $3 u, 4 u$ and $5 u$ ) and there would be neither isosceles, nor half-equilateral triangles. A possible solution allowing one to maintain Timaeus' basic triangles would be to admit the existence of several atomic lines (in addition to $u$, at least $u \sqrt{ } 2$ and $u \sqrt{ } 3$ ), but then it would not be possible to superimpose two lines, even two straight ones. Otherwise, the atomic line of length $u$ will divide the atomic line of length $u \sqrt{ } 2$ into a line of length $u$ and a line of length $u(\sqrt{ } 2-1)$. Since the latter is obviously less than $u \sqrt{ } 2$, the line of length $u \sqrt{ } 2$ would not be atomic. However, it would then, not be possible to compare even straight lines, as is done in proposition I.4 of Euclid's Elements, so that the fundamental theory of equality of triangles would entirely collapse.

${ }^{133}$ On the Heavens III, 1, 299a1-300a19. Cf. also Simplicius' commentary on these lines in Simplicius-2, 562.21563.25. This conclusion can even be extended to time (300a7-15).

${ }^{134}$ For this extremely controversial question, cf. for instance, Miller (2003), p. 19; Gregory (2003), p. 29, 31-32.
} 


\section{Conclusion}

We have tried to show how misleading it is to link Plato to any form of atomism, including in the subtler form of a 'mathematical atomism'. It is difficult to understand even which kind of 'atom' the partisans of such a linkage have in mind, since they almost never define this term precisely. ${ }^{135}$ Indeed, in the case of 'mathematical atomism', there are at least six forms of 'atoms' associated with the different kinds of 'mathematical atomism':

1) The basic triangles possessing some depth, i.e. plates.

2) The elementary regular polyhedrons (cubes, tetrahedrons, octahedrons, icosahedrons).

3) The 'indivisible lines' as used in the works of Cavalieri and/or Archimedes.

4) The 'mathematical atoms' of Democritus.

5) The 'indivisible triangles', a variation of the triangles made of 'indivisible lines' that Aristotle criticized, which the pseudo-Aristotelian treatise combats.

6) Timaeus' basic right isosceles or half-equilateral triangles. ${ }^{136}$

Whatever the choice, none of these interpretations is consistent with Timaeus' account, and, what is more, the multiplicity of the possible meanings adds a strong element of confusion. Atomism proposes a means to reduce the complexity of the universe to particles, involving either no mathematics ${ }^{137}$ or very primitive one. For Timaeus, the opposite is true. His construction entails a huge simplification of the infinite diversity of the universe, even with respect to the atomists' theory.

However, this is not without its own challenges: the insertion of geometry in physics, something Aristotle ${ }^{138}$ and subsequent thinkers were to reject. This entails the existence of the khora, intermediate between the sensible and the intelligible worlds, about which one know almost nothing, except that it is the indeterminate third 'genus', where the 2-dimensional basic right triangles are able to assemble together to compose the elementary regular polyhedrons. As the khor $\mathrm{r}$ is an intermediate between the sensible and intelligible, the two basic right triangles, from which all the elementary particles are formed, are intermediate between mathematics and physics, as mathematical figures inside the physical world. ${ }^{139}$ All this is lost when one speaks of 'atomic triangles'. The qualification itself of 'mathematical atomism' adds to the difficulties to understand Plato's Timaeus in general, the khorra in particular. Namely, the cosmology of the Timaeus may be characterized on the contrary, as an anti-atomism with mathematical foundations.

\section{Appendix}

The laws of transformation for air and fire entail that one particle of air (a regular octahedron) may change into two particles of fire (regular tetrahedrons) with the same faces (i.e. the same

\footnotetext{
${ }^{135}$ Even the trivial assertion that Timaeus' basic triangles are atomic because they are indivisible, is problematic. Indeed, it would entail that anything indivisible is an atom. Then, the points would be atoms, and Aristotle criticism would be right: Timaeus' universe would be filled by points (cf. supra, note 133). Moreover, Timaeus suggests indeed that these triangles are not even the last components of the universe, (cf. supra, §IV.iii)), which would be hard to reconcile with such a definition of 'atom'.

${ }^{136}$ For this last statement that challenges a popular view, we refer in particular to §IV.2.iv), supra.

${ }^{137}$ Cf. supra, §I.1.

138 'The transition, in Plato's theory, from the 'abstractions' of geometry to the 'material' entities that underlie our sensible experience, was for Aristotle the major scandal in Plato's physical theory;' (O'Brien (1984), II, p. 287).

${ }^{139}$ This is precisely a criticism of Aristotle against the cosmology of the Timaeus: the existence of what he calls a 'suspension' (' $\pi \alpha \rho \alpha \omega^{\prime} \eta \sigma \iota \varsigma$ ') of triangles inside the physical world of 3-dimensional bodies (On the Heavens, III, 7, 306a20-23).
} 
equilateral triangles). However, the volume of one octahedron is four times the volume of a tetrahedrons with the same faces. We will give two methods certainly known by the geometers of the $5^{\text {th }}$ century BCE.

1) By elementary cuttings:

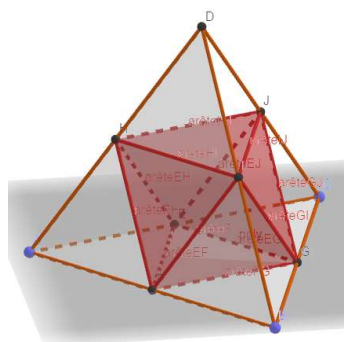

Figure 7

The above figure ${ }^{140}$ shows that the large tetrahedron of vertex D is the sum of four smaller tetrahedrons plus an octahedron of half edges, the vertices of the octahedrons being the middle of the sides of the large tetrahedron. Thus, the faces of the smaller tetrahedrons and of the octahedron are the same equilateral triangles. Since the volume $U$ of the large tetrahedron is eight times the volume $V$ of the smaller one, we obtain:

$U=8 V=4 V+W$ thus $W=4 V$.

Hence, the volume of the regular octahedrons is four times the volume of the regular tetrahedron with the same faces (or edges).

2) Computation by Democritus' formula:

Democritus' formula states that the volume of a pyramid or the cone is one third the product of its base by its height (cf. infra, §III.2.i)).

i) The base of the tetrahedron is the equilateral triangle of side $a$. Thus, its area is:

$(a \times a \sqrt{3} / 2) / 2=a^{2} \sqrt{3} / 4$.

The height $h$ of the tetrahedron is by Pythagoras' theorem:

$h^{2}=a^{2}-(a \sqrt{3} / 3)^{2}=2 / 3 a^{2}$, thus $h=a \sqrt{2} / \sqrt{3}$.

Thus its volume $V=1 / 3\left(a^{3} \sqrt{2} / 4\right)$

ii) The octahedron is the addition of two pyramids, each of base the square of side $a$, and of height $a / \sqrt{2}$. Its volume is then:

$$
W=1 / 3\left(2 a^{2} \times a / \sqrt{2}\right)=1 / 3\left(2 a^{3} / \sqrt{2}\right) \text {. }
$$

Thus the ratio of the octahedron to the tetrahedron of same edge is: $W / V=(2 / \sqrt{2}) /(\sqrt{2} / 4)=4$.

Hence, from the point of view of the volumes, one particle of air would have to change into four, not two, particles of fire (and vice-versa). With respect to the volumes, the laws of transformations between the elements would be wrong, something which was certainly wellknown by any mathematician at Socrates' times, a fortiori by Plato. However, some commentators and historians of mathematics have claimed that Plato did not know that his construction was wrong because of the primitive stage of mathematics even at Plato's times, i.e. the $4^{\text {th }}$ century BCE. Probably because they focused on the icosahedron, which ratio to the three other polyhedrons is more difficult to compute. However, the case of fire and air is enough to show that the laws of transformation are inconsistent with a rule of immutable volumes. This entails that Timaeus was not interested by the volumes of the bodies but by the surfaces limiting them.

\footnotetext{
${ }^{140}$ We used Geogebra to draw it.
} 


\section{Bibliography}

Except when indicated otherwise, Aristotle's translations are quoted from the Works of Aristotle, edited by W. Ross, Clarendon Press; translations of Plato's Timaeus are from Zeyl's translation, in Plato's Complete Works edited by J. Cooper and D. Hutchinson. We have used Heath's translation for Euclid's Elements.

Allen, Reginald, Plato's Parmenides (transl.), Yale Univ. Press, 1997 (1983) = Allen (1983)

Andersen, Kirsti, “Cavalieri's Method of Indivisibles”, Arch. Hist. Exact Sci., 31, 4, 1985, p. 261-367 = Andersen (1985)

Artmann, Benno and Schäffer, Lothar, "On Plato's "fairest" triangles, Timaeus 54a", Historia matematica, 20, 1993, p. 255-264 = Artmann-Schäffer (1993)

Bailey, Cyril, Epicurus, The extant remains, Oxford Univ. Press, 1926 = Bailey (1926)

Barnes, Jonathan, The Presocratic Philosophers, Routledge, 1982 (1979) = Barnes (1979)

Bell, John, "Continuity and Infinitesimals", The Stanford Encyclopedia of Philosophy (Summer 2017 Edition), Edward N. Zalta (ed.), URL = https://plato.stanford.edu/archives/sum2017/entries/continuity/= Bell (2017)

Bell, John, The Continuous, the Discrete and the Infinitesimal in Philosophy and Mathematics, Springer, $2019=$ Bell (2019)

Berryman, Sylvia, "Democritus", The Stanford Encyclopedia of Philosophy, Edward N. Zalta (ed.), Winter 2016 Edition = Berryman (2016)

Blay, Michel and Egidio, Festa, "Mouvement, continu, composition des vitesses au XVII ${ }^{\text {ème }}$ siècle", Archives internationales d'histoire des sciences, 48, 149, 1998, p. 65-118 = Blay-Egidio (1998)

Boyer, Carl, A History of Mathematics, Wiley, 1968 = Boyer (1968)

Boyer, Carl, The History of Calculus, Dover, 1949 = Boyer (1949)

Broadie, Sarah, Nature and Divinity in Plato's Timaeus, Cambridge Univ. Press, $2011=$ Broadie (2011)

Bruins, Evert, "La chimie du Timée", Revue Métaphysique et Morale, 56, 1951, p. 269-282 = Bruins (1951)

Brunschwig, Jacques, "Épicure”, in Philosophie grecque, M. Canto (ed.), PUF 1997, p. 475-510= Brunschwig (1997)

Burnett, John, Early Greek Philosophy, A \& C Black, 1945 (1892) = Burnett (1892)

Cavalieri, Bonaventura, Lo Specchio ustorio overo trattato delle Settioni coniche et alcuni loro mirabili effetti, Ferroni, 1632 = Cavalieri (1632)

Cavalieri, Bonaventura, Geometria indivisibilibus continuorum nova quadam ratione promota, Bologna, 1635 (Italian translation by L. Lombardo-Radice under the title: Geometria degli indivisibili di Bonaventura Cavalieri, Unione Tipografico-Editrice Torinese, 1966) = Cavalieri (1635)

Cavalieri, Bonaventura, Exercitationes geometricae sex, Bononiae-J. Montius, 1647 = Cavalieri (1647)

Charlton, William, "Prime Matter: A Rejoinder", Phronesis, 28, 2 (1983), p. 197-211 = Charlton (1983)

Cherniss, Harold, Aristotle's Criticism of Presocratic Philosophy, John Hopkins Press, $1935=$ Cherniss (1935)

Cherniss, Aristotle's Criticism of Plato and the Early Academy, Baltimore, $1944=$ Cherniss (1944), p.

121 ,

Cleary, John, Aristotle on Mathematics, Brill, 1995 = Cleary (1995)

Cleary, John, Studies on Plato, Aristotle and Proclus, Collected Essays on Ancient Philosophy of John J. Cleary, J. Dillon, B. O’Byrne, F. O’Rourke (ed.), Brill, 2013 = Cleary (2013)

Conche, Marcel, Lucrèce et l'expérience, PUF, 2011 = Conche (2011)

Cornford, Francis, Plato's Cosmology-The Timaeus of Plato, Hackett, 1977 (1937) = Cornford (1937)

Demtröder, Wolfgang, Atoms, Molecules and Photons, 2006 = Demtröder (2006)

Diels, Hermann and Kranz, Walther, Die Fragmente der Vorsokratiker, $5^{\text {th }}$ ed., Weidmannsche,1934-1937 = DK Eusebius of Caesarea, Praeparatio Evangelica (Preparation for the Gospel, transl. E. Gifford, Oxford Univ. Press, 1903) $=$ Eusebius

Falcon, Andrea, Aristotle and the Science of Nature, Cambridge Univ. Press, $2005=$ Falcon (2005)

Federspiel, Michel, "Notes exégétiques et critiques sur le traité pseudo-Aristotélicien des lignes insécables", Revue des Études Grecques, 94, 447-449, 1981, p. 502-513 = Federspiel (1981) 
Federspiel, Michel, 'Notes sur le traité passage 970 a 26-33 du traité pseudo-aristotélicien des lignes insécables', in Mathématiques dans l'Antiquité, J.Y. Guillaumin (ed.), 1992, p. 44-50 = Federspiel (1992)

Furley, David, Two Studies in the Greek atomists, Princeton Univ. Press, 1967

Furley, David, The Greek Cosmologists, I, The Formation of the Atomic Theory and its Earliest Critics, Cambridge Univ. Press, $1987=$ Furley (1987)

Gadamer, Hans-Georg, Beginning of Knowledge, R. Coltman (transl.), Continuum, 2002 = Gadamer (2002)

Galilei, Galileo, Le Opere di Galileo Galilei, A. Favaro (ed.), Barbèra, 1905 = Galilei (1905)

Greenaway, Frank, John Dalton and the Atom, Cornell University Press, 1966 = Greenaway (1966)

Gregory, Andrew, Plato's Philosophy of Science, Bloomsbury Academic, 2001 = Gregory (2001)

Gregory, Andrew, "Aristotle and some of his commentators on the "Timaeus" Receptacle", Bull. Inst. of Classical Studies, 78, 2003, p. 29-47 = Gregory (2003)

Guthrie, William, A History of Greek Philosophy, II, Cambridge Univ. Press, 1980 (1965) = Guthrie (1965)

Hahm, David, “Chrysippus' solution to Democritus' Dilemma of the Cone”, Isis, 63, 2, 1972, p. 205-220= Hahm (1972)

Heath, Thomas, The Works of Archimedes, Cambridge Univ. Press, $1897=$ Heath (1897)

Heath, Thomas, The Method of Archimedes recently discovered by Heiberg, Cambridge Univ. Press, $1912=$ Heath (1912)

Heath, Thomas, The Thirteen books of the Elements, vol. I, Cambridge, $1908=$ Heath (1908)

Heath, Thomas, A History of Greek Mathematics, I, Clarendon Press, $1921=$ Heath (1921)

Heath, Thomas, Mathematics in Aristotle, Clarendon Press, 1979 (1949) = Heath (1949)

Heiberg, Johan, Archimedis Opera omnia, II, Teubner = Heiberg (1913)

Heisenberg, Werner, Physics and Philosophy-The Revolution In Modern Science, Harper, 2007 (1962) = Heisenberg (1962)

Heisenberg, Werner, "Tradition in Science”, Bulletin of the Atomic Scientists, 1973, 29, 10, p. 4-10= Heisenberg (1973)

Hett, Walter (transl.), “On indivisible lines”, in Aristotle’s Minor works, Harvard Univ. Press, $1955(1936)=$ Hett (1936)

Imhausen, Annette, Mathematics in Ancient Egypt. A Contextual History, Princeton Univ. Press, $2016=$ Imhausen (2016)

Diogenes Laertius, The lives and opinions of eminent philosophers, text and transl. by Robert Hicks, Harvard Univ. Press, 1925 = Diogenes Laertius

Joachim, Harold (transl.), "De Lineis insecabilibus", in The Works of Aristotle, J. Smith and W. Ross (ed.), Clarendon Press, 1908 = Joachim (1908)

Kepler, Joannis, Opera Omnia, C. Frisch (ed.), III, Heyder \& Zimmer, $1858=$ Kepler (1858)

Leggett, Anthony, "Plato's Timaeus: Some Resonances in Modern Physics and Cosmology", in One Book, the

Whole Universe: Plato's Timaeus Today, R. Mohr, B. Sattler (ed.), Parmenides, 2010, p. 31-36= Zeyl (2010)

Leone, G., Epicuro, Della natura, libro XIV, Cronache Ercolanesi 18, 17-107. = Leone (1984)

Lucretius, On the Nature of Things, M. Smith (transl.), Hacket, 2001 (1969) = Lucretius

Luria, Salomon, "Die Infinitesimallehre der antiken atomisten”, Quellen und Studien zur Geschichte der

Mathematik, 2, 1932, p. 106-185 = Luria (1932)

Luthy, Christoph, "The Fourfold Democritus on the Stage of Early Modern Science", Isis, 91, 3, 2000, p. $443-479$ = Luthy (2000)

Makin, Stephen, "The Indivisibility of the Atom", Archiv für Geschichte der Philosophie, 71, 1989, p. 125-49= Makin (1989)

Martin, Thomas, Études sur le 'Timée' de Platon, II, Ladrange, Paris, 1841 = Martin (1841)

Mau, Jürgern, Zum Problem des Infinitesimalen bei den antiken atomisten, Akademie-Verlag, $1954=$ Mau (1954)

Miller, Dana, The third kind in Plato s Timaeus, Vandenhoeck \& Ruprecht, $2003=$ Miller (2003)

Morel, Pierre-Marie, Atome et nécessité. Démocrite, Epicure, Lucrèce, PUF, $2000=$ Morel (2000)

Morel, Pierre-Marie, "Démocrite et les sections du cône (68b155), problèmes généraux d'interprétation", in Les anciens savants, J.-F. Pradeau and P.-M. Morel (ed.), Les cahiers philosophiques de Strasbourg, 12, p. 73-87 = Morel (2001)

Netz, Reviel, The Works of Archimedes, I, transl. R. Netz, Cambridge Univ. Press, 2004 = Netz (2004)

Netz, Reviel, "Were There Epicurean Mathematicians?", in Oxford Studies in Ancient Philosophy, 49, p. 283-319, $2015=\operatorname{Netz}(2015)$

O'Brien, Denis, "La taille et la forme des atomes dans les systèmes de Démocrite et d'Épicure", Revue Philosophique de la France et de l'Étranger, 172, 2, 1982, p. 187-203 = O'Brien (1982) 
O'Brien, Denis, Theories of Weight in the Ancient World, 2 vol., Brill, 1984 = O'Brien (1984)

O'Brien, Denis, "Démocrite à l'Académie ?", in Democritus: Science, The Arts, and the Care of the Soul, A.

Brancacci-P.M. Morel (ed.), Brill, 2007, p. 239-263 = O’Brien (2007)

Pascal, Euvres complètes, II, Gallimard, 2000 = Pascal (2000)

Pohle, William, "The mathematical foundations of Plato's atomic physics", Isis, 62, 1971, p. 36-47= Pohle (1971)

Politis, Vasilis, Aristotle and the Metaphysics, Routledge, $2004=$ Politis (2004)

Proclus, A Commentary on the First Book of Euclid's Elements, transl. G. Morrow, Princeton Univ. Press, 1970 $=$ Proclus

Roberval, Gilles Personnes de, Divers ouvrage de M. de Roberval, Hachette-BNF, 2012 (1693) = Roberval (1693)

Ross, David, Aristotle's Metaphysics, (text and commentary), 2 Vol., Oxford Univ. Press, $1924=$ Ross (1924)

Salem, Jean, L'atomisme antique : Démocrite, Épicure, Lucrèce, Flammarion, 2013 (1997) = Salem (2013)

Salem, Jean, Les atomistes de l'Antiquité, Flammarion, 2013 (1997) = Salem (1997)

Sedley, David, "Epicurus and the Mathematicians of Cyzicus", Chronache Ercolanesi, 6, 1976, Gaetano Macchiavoli, p. 41-83 = Sedley (1976)

Sedley, David, "The Origins of Stoic God", in Traditions of Theology, D. Frede and A. Laks (ed.), Brill, 2002, p. 41-83 = Sedley (2002)

Sedley, David, “On Generation and Corruption I.2”, in Aristotle: On Generation and Corruption, Book 1, F. De Haas-J. Mansfeld (ed.), Clarendon Press, 2004, p. 65-89 = Sedley (2004)

Sedley, David, “Atomism's Eleatic Roots”, in The Oxford Handbook of Presocratic Philosophy, P. Curd and D. Graham (eds.), Oxford University Press, 2008, p. 305-332 = Sedley (2008)

Seung, T., Plato rediscoverd: Human Value and Social Order, Rowman and Littlefield, $1996=$ Seung (1996)

Simplicius-1, In Aristotelis Physica commentaria, H. Diels (ed.), Berolini, 1882-1895 = Simplicius-1

Simplicius-2, In Aristotelis 'De caelo' commentaria, J. Heiberg (ed.), Berolini, 1894 = Simplicius-2

Smith, Mark, “Galileo's Theory of Indivisibles: Revolution or Compromise?”, Journal of the History of Ideas, 37, 4, 1976, pp. 571-588 = Smith (1976)

Solmsen, Friedrich, "Plato and science", in Interpretations of Plato: a Swarthmore Symposium, Helen North (ed.), Brill, 1977, p. 86-105 = Solmsen (1977)

Taylor, Alfred, Plato-The man and his Work, Methuen, 1955 (1926) = Taylor (1926)

Taylor, Alfred, A Commentary on Plato's Timaeus, Clarendon Press, $1928=$ Taylor (1928)

Taylor, Christopher, The atomists Leucippus and Democritus: Fragments, a text and translation with a commentary, Univ. of Toronto press, 1999 = Taylor (1999)

Tredennick, Hugh, Aristotle's Metaphysics, Harvard Univ. Press, 1933 = Tredennick (1933)

Visintainer, John, “A Potential Infinity of Triangle Types On the Chemistry of Plato's Timaeus”, Hyle, 4, 2, 1998, p. 117-128 = Visintainer (1998)

Vlastos, Gregory, "The Disorderly Motion in the Timaios", The Classical Quarterly, 33, 2, 1939, pp. 71-83 (reprinted in Studies in Greek Philosophy, II, D. Graham (ed.), Princeton Univ. Press, 1995, p. 247-264) = Vlastos (1939)

Vlastos, Gregory, "Minimal Parts in Epicurean atomism”, Isis, 56, 1965, p. 121-147, (repr. in Studies in Greek Philosophy, II, D. Graham (ed.), Princeton Univ. Press, 1995, p. 285-314) = Vlastos (1965)

Vlastos, Gregory, Plato's Universe, Intr. L. Brisson, Parmenides, 1995 = Vlastos (1995)

Vlastos, Gregory, “The role of Observation in Plato's Conception of Astronomy, in Studies in Greek Philosophy, II, D. Graham (ed.), Princeton Univ. Press, 1995, p. 247-246 = Vlastos (1995)

Walker, Evelyn, A Study of the Traité des Indivisibles of Gilles Personne de Roberval, Columbia Univ., $1932=$ Walker (1932)

Whitt, Lancelot, Essay on atomism, Wesleyan Univ. Press, $1961=$ Whitt (1961)

Zeyl, Donald, "Visualizing Platonic Space", in One Book, the Whole Universe: Plato's Timaeus Today, R. Mohr, B. Sattler (ed.), Parmenides, 2010, p. 117-130= Zeyl (2010) 